\title{
Reduced Excitatory Neurotransmission and Mild Autism-Relevant Phenotypes in Adolescent Shank3 Null Mutant Mice
}

\author{
Mu Yang, ${ }^{1}$ Ozlem Bozdagi, ${ }^{2}$ Maria Luisa Scattoni, ${ }^{1}$ Markus Wöhr, ${ }^{1}$ Florence I. Roullet, ${ }^{1}$ Adam M. Katz, ${ }^{1}$ \\ Danielle N. Abrams, ${ }^{1}$ David Kalikhman, ${ }^{1}$ Harrison Simon, ${ }^{1}$ Leuk Woldeyohannes, ${ }^{1}$ James Y. Zhang, ${ }^{1}$ Mark J. Harris, ${ }^{1}$ \\ Roheeni Saxena, ${ }^{1}$ Jill L. Silverman, ${ }^{1}$ Joseph D. Buxbaum, ${ }^{2}$ and Jacqueline N. Crawley ${ }^{1}$ \\ ${ }^{1}$ Laboratory of Behavioral Neuroscience, National Institute of Mental Health, Bethesda, Maryland 20892, and ${ }^{2}$ Seaver Autism Center for Research and \\ Treatment, and Laboratory of Molecular Neuropsychiatry, Department of Psychiatry, Mount Sinai School of Medicine, New York, New York 10029
}

\begin{abstract}
Mutations in the synaptic scaffolding protein gene SHANK3 are strongly implicated in autism and Phelan-McDermid 22q13 deletion syndrome. The precise location of the mutation within the Shank3 gene is key to its phenotypic outcomes. Here, we report the physiological and behavioral consequences of null and heterozygous mutations in the ankyrin repeat domain in Shank 3 mice. Both homozygous and heterozygous mice showed reduced glutamatergic transmission and long-term potentiation in the hippocampus with more severe deficits detected in the homozygous mice. Three independent cohorts were evaluated for magnitude and replicability of behavioral endophenotypes relevant to autism and Phelan-McDermid syndrome. Mild social impairments were detected, primarily in juveniles during reciprocal interactions, while all genotypes displayed normal adult sociability on the three-chambered task. Impaired novel object recognition and rotarod performance were consistent across cohorts of null mutants. Repetitive self-grooming, reduced ultrasonic vocalizations, and deficits in reversal of water maze learning were detected only in some cohorts, emphasizing the importance of replication analyses. These results demonstrate the exquisite specificity of deletions in discrete domains within the Shank3 gene in determining severity of symptoms.
\end{abstract}

\section{Introduction}

Shank3 is a scaffolding protein at the postsynaptic density that modulates dendritic spine morphology and synaptic signaling through glutamate receptors and interactions with the cytoskeleton (Böckers et al., 2001; Roussignol et al., 2005; Baron et al., 2006; Bertaso et al., 2010; Durand et al., 2012). Shank proteins bind to Homer, actin-binding protein Abp1, and cortical actinbinding protein, which promote polymerization of the actin cytoskeleton and mediate synaptic plasticity (Sheng and Kim, 2000; Boeckers et al., 2002; Verpelli et al., 2011). Mutations in SHANK3 lead to global developmental delay and autism (Durand et al., 2007, 2012; Moessner et al., 2007; Abu-Elneel et al., 2008; Gauthier et al., 2009; Houlihan et al., 2009; Qin et al., 2009; Sykes et

Received Dec. 8, 2011; revised March 6, 2012; accepted March 8, 2012.

Author contributions: M.Y., M.L.S., J.D.B., and J.N.C. designed research; M.Y., 0.B., M.W., F.I.R., A.M.K., D.N.A., D.K., H.S., L.W., J.Y.Z., M.J.H., R.S., and J.L.S. performed research;M.Y., M.L.S., M.W., F.I.R., A.M.K., D.N.A., D.K., H.S., J.Y.Z., M.J.H., R.S., and J.L.S. analyzed data; M.Y. and J.N.C. wrote the paper.

This work was supported by The Simons Foundation and the National Institute of Mental Health Intramural Research Program.

Correspondence should be addressed to Dr. Mu Yang, Laboratory of Behavioral Neuroscience, Intramural Research Program, National Institute of Mental Health, National Institutes of Health, Building 35, Room 1C-903/909, Mail Code 3730, Bethesda, MD 20892-3730. E-mail: yangmu@mail.nih.gov.

M. L. Scattoni's present address: Department of Cell Biology and Neuroscience, Istituto Superiore di Sanità, I-00161 Rome, Italy.

M. Wöhr's present address: Department of Experimental and Physiological Psychology, Philipps University of Marburg, D-35032 Marburg, Germany.

DOI:10.1523/JNEUROSCI.6107-11.2012

Copyright $\odot 2012$ the authors $\quad 0270-6474 / 12 / 326525-17 \$ 15.00 / 0$ al., 2009). Furthermore, SHANK3 haploinsufficiency is central to the behavioral manifestations of the 22q13 deletion found in Phelan-McDermid syndrome (Bonaglia et al., 2001; Delahaye et al., 2009; Dhar et al., 2010; Misceo et al., 2011), a neurodevelopmental disorder characterized by developmental delay, language impairment, and autistic features (Phelan, 2008).

To evaluate the behavioral and biological consequences of Shank3 mutations, we and others generated mice with targeted mutations in either the ankyrin repeat domain, the PDZ domain, or the C-terminal domain. Shank3 mutant mice displayed reduced AMPA-mediated neurotransmission (Bozdagi et al., 2010), reduced hippocampal long-term potentiation (Bozdagi et al., 2010; Bangash et al., 2011; Peça et al., 2011; Wang et al., 2011), altered PSD composition and dendritic spine morphology in the hippocampus or striatum (Peça et al., 2011; Wang et al., 2011), impaired social behaviors (Bozdagi et al., 2010; Bangash et al., 2011; Peça et al., 2011; Wang et al., 2011), cognitive deficits (Wang et al., 2011), and repetitive self-grooming and skin lesions (Peça et al., 2011), depending on the precise location of the mutation within the gene sequence.

Our previous report focused on electrophysiological responses and two aspects of social behaviors in Shank3 heterozygotes with a mutation at the ankyrin domain (Bozdagi et al., 2010). To fully understand the consequences of SHANK3 mutations at the ankyrin site across the range of behavioral phenotypes reported in autism and Phelan-McDermid syndrome, we undertook a considerably more comprehensive and longitudinal be- 
havioral analysis of the same line of Shank3 mice as described in the study by Bozdagi et al. (2010) on parameters relevant to autism and Phelan-McDermid syndrome. Domains and tasks included developmental milestones, pup ultrasonic vocalizations, juvenile reciprocal social interactions in freely moving dyads, adult sociability on automated three-chambered social approach, adult male ultrasonic vocalization in response to female pheromones and during male-female interactions, elevated plus-maze and light $\leftrightarrows$ dark anxiety-related behaviors, water maze learning, fear conditioning, novel object recognition, neurological reflexes, open-field locomotion, footprint ataxia, rotarod motor coordination and balance, grip strength, acoustic startle and prepulse inhibition, olfactory sensitivity to social and nonsocial odors, pain sensitivity, self-grooming, and control measures of general health. Although the human SHANK3 mutation is hemizygous, for completeness we examined electrophysiological and behavioral parameters in null mutant mice, along with their heterozygous and wild-type littermates. To evaluate the robustness of behavioral abnormalities, two cohorts representing all three genotypes were compared, as well as an earlier group of heterozygotes and wild types. Our findings indicate that mice with mutations at the Shank3 ankyrin domain exhibited relatively mild behavioral abnormalities, including deficits in some parameters of juvenile reciprocal social interaction, elevated selfgrooming, and impairments on components of cognitive tasks. Degrees of impairments varied across cohorts, highlighting the importance of testing multiple cohorts.

\section{Materials and Methods}

Subjects. Mice with mutations in the gene coding for the Shank3 protein were generated at the Mount Sinai School of Medicine as previously described (Bozdagi et al., 2010). The mouse used in the present study was the same as the one described in the study by Bozdagi et al. (2010). Briefly, Bruce4 C57BL/6 embryonic stem cells were used to generate a mouse line with a deletion of the ankryin repeat region of the Shank3 gene. Two loxP sites were inserted before exon 4 and after exon 9, to encompass the region that encodes the ankyrin repeats, with the selection cassette, flanked by FRT sites, excised by FLP recombinase. For mice used in the present behavioral studies, the floxed allele was excised by a ubiquitously expressed Cre and a line maintained with a deletion of exons 4 through 9. This strategy resulted in constitutive deletion of the Shank $3_{\alpha}$ isoform.

Shank3 wild-type $(+/+)$ and heterozygote $(+/-)$ breeding pairs were imported from Mount Sinai to NIMH, where three cohorts of offspring were generated and behaviorally tested in Bethesda, Maryland. The first group was generated by mating the original $+/+$ and $+/-$ breeders, consisted of two genotypes, $+/+$ and $+/-$ (WT-HET cohort). A small subset of behavioral results from these mice was reported previously (Bozdagi et al., 2010). Heterozygous males and females from this first group were mated to generate new Cohorts 1, 2, and 3, each of which consisted of three genotypes, $+/+,+/-$, and $-/-$. Cohorts 1 and 2 were used for the majority of behavioral experiments. Cohort 3 was used for detailed analysis of motor learning and for replicating novel object recognition. Genotype was determined by PCR of mouse tail DNA, with primers:5loxp (AGAGTGACCAGGCTCAGGAT), 3int (AACCGTCAAT GCCCCTGCGT), and 3loxp (GTTCAGTCCACACAGGCTCTT), in a 1:1:1 mixture. The wild-type allele and the mutated allele were 600 and $320 \mathrm{bp}$ in size, respectively. Wild-type mice were genotyped by the absence of the mutated allele product. The PCR process begins by heating the samples at $94^{\circ} \mathrm{C}$ for $2 \mathrm{~min}$. The second stage consists of 35 cycles (at $94^{\circ} \mathrm{C}$ for $30 \mathrm{~s}$, then at $60^{\circ} \mathrm{C}$ for $45 \mathrm{~s}$, then at $72^{\circ} \mathrm{C}$ for $60 \mathrm{~s}$ ). The samples were then heated at $72^{\circ} \mathrm{C}$ for $7 \mathrm{~min}$ at the end of the PCR process. Mice were weaned at $21 \mathrm{~d}$ of age, and group housed by sex in cages of two to four littermates per cage. Standard rodent chow and tap water were available ad libitum. In addition to standard bedding, a Nestlet square and a cardboard tube were provided in each cage. The colony room was maintained on a $12 \mathrm{~h}$ light/dark cycle with lights on at 7:00 A.M., and at $\sim 20^{\circ} \mathrm{C}$ and $55 \%$ humidity. All experiments were conducted between 9:00 A.M. and 5:00 P.M. All procedures were approved by the Mount Sinai School of Medicine and the NIMH Animal Care and Use Committees.

Extracellular recording. Methods were conducted as previously described (Bozdagi et al., 2010). Acute hippocampal slices were prepared from 4- to 6-week-old homozygous, heterozygous, and wild-type littermate mice. All experiments were conducted at $32^{\circ} \mathrm{C}$ on two to three slices per animal. Field EPSPs (fEPSPs) were recorded from stratum radiatum in CA1, evoked by stimulation of the Schaffer collaterals every $30 \mathrm{~s}$ with $100 \mu$ s pulses. LTP was induced with TBS (10 theta bursts of four pulses at $100 \mathrm{~Hz}$, with an interval of $200 \mathrm{~ms}$ ). Long-term depression (LTD) was induced by a low-frequency stimulation protocol ( 900 pulses at $1 \mathrm{~Hz}$ for $15 \mathrm{~min}$, or by paired-pulse low-frequency stimulation $(1 \mathrm{~Hz}$ for $15 \mathrm{~min}$; $50 \mathrm{~ms}$ interstimulus interval).

Behavioral phenotyping. Comprehensive behavioral phenotyping was conducted in male and female mice as previously described (Miyakawa et al., 2001; Paylor et al., 2001; Wrenn et al., 2004; Bailey et al., 2007; Chadman et al., 2008; Silverman et al., 2011). Paw tattoo identification markings were recorded after the behavioral test in all cases, to ensure that investigators were blind to genotype during all test sessions. For all tasks, all genotypes were tested on the same day in randomized order. Pups were tested for developmental milestones and separation-induced ultrasonic vocalizations between postnatal day 2 and postnatal day 14. Juveniles were tested for reciprocal social interactions between 21 and $25 \mathrm{~d}$ of age. Young adults were tested in the elevated plus-maze at 6 weeks of age. Adults were tested for sociability in our automated three-chambered social approach task between 10 and 16 weeks of age (WT-HET cohort and Cohort 1) or at 6-7 weeks of age (Cohort 2). One week after the social approach test, male subjects were tested for male-female reciprocal social interaction with concomitant ultrasonic vocalizations. One week later, male subjects were tested for social scent marking with concomitant recording of ultrasonic vocalizations. General health, neurological reflexes, vision, hearing, sensorimotor gating, nociception, open-field activity, rotarod motor learning, grip strength, gait, light $\leftrightarrows$ dark exploration test, repetitive self-grooming, and novel object recognition were conducted between 8 and 16 weeks of age, in that general order. Fear conditioning and Morris water maze were conducted at the end of this test battery, to avoid confounds of these two relatively stressful cognitive tasks on social and other behaviors (Steiner et al., 2001; Wrenn et al., 2004; Bevins and Besheer, 2006; Bailey et al., 2007; Moy et al., 2007; Bainbridge et al., 2008; Chadman et al., 2008; McFarlane et al., 2008; Scattoni et al., 2008a, 2011; Stack et al., 2008; Yang et al., 2009, 2011a,b; Bozdagi et al., 2010; Wöhr et al., 2011).

General health and neurological reflexes. Measures of general health and neurological reflexes were evaluated in adult mice as previously described (Steiner et al., 2001; Wrenn et al., 2004; Holmes et al., 2005; Bailey et al., 2007; Crawley et al., 2007; Chadman et al., 2008; Yang et al., 2009; Silverman et al., 2011). General health was assessed by fur condition, whisker condition, body weight, body temperature, body and limb tone, and three 15 min observations of home cage behaviors at different phases of the circadian cycle. Neurological reflexes were assessed by forepaw reaching, righting reflex, trunk curl, whisker twitch, pinna response, eyeblink response, and auditory startle. Behavioral reactivity was evaluated as responsiveness to petting, intensity of dowel biting, and level of sonic vocalization when handled. Empty cage behaviors were scored by placing the mouse into a clean, empty cage and noting wild running, stereotypies, and excessive exploration levels.

Motor functions: grip strength, wire hang, open-field exploratory activity, and gait. Measures of neuromuscular and motor functions were evaluated as previously described (Holmes et al., 2001; Wrenn et al., 2004; Bailey et al., 2007; Chadman et al., 2008; Yang et al., 2009; Silverman et al., 2011). Forelimb grip strength was tested with a Strength Meter (Columbus Instruments). A metal triangle grasping bar was fitted to a force transducer, which connected to the peak amplifier. The grasping bar was positioned so that the bar was parallel to the horizontal plane. The mouse was held by the tail and carried toward the apparatus until it spontaneously reached out its forepaws to grab onto the bar. The mouse's tail was then gently pulled back, with its body parallel to the horizontal plane. The 
force at the moment when the mouse lost its grip was recorded as the peak tension. The test was repeated three consecutive times for each mouse. The mean of all trials and the largest value from all trials were recorded as grip strength parameters. To measure wire hang, a mouse was placed on a wire cage lid. The cage lid was inverted and held $\sim 50 \mathrm{~cm}$ above a cage lined with clean bedding, for a maximum of $60 \mathrm{~s}$. Latency to fall was recorded for each mouse. General exploratory locomotion in a novel open-field environment was tested in a VersaMax Animal Activity Monitoring System (AccuScan) for a 10 min session (Cohort 1 ) or a 30 min session (Cohort 2). Total distance traversed in the arena, horizontal activity detected by adjacent beam breaks in the lower photocell panels, vertical activity detected by beam breaks in the $z$ upper photocell panels, and time spent in the center were automatically measured by software linked to the photocell detectors. Gait was evaluated using the footprint test. The subject's forepaws and hindpaws were respectively painted with green and red nontoxic paint (Crayola). The mouse was then released onto a 50-cm-long, 20-cm-wide runway covered with a piece of white paper (Strathmore Artist Papers), where the subject walked through a tunnel $(10 \times 10 \times 30 \mathrm{~cm})$ at the end of the runway. Forepaw width, hindpaw width, and stride length were measured to detect irregular gait or ataxia.

Automated three-chambered social approach task. Social approach was assayed in our automated three-chambered apparatus (NIMH Research Services Branch, Bethesda, MD) using methods previously described (Crawley et al., 2007; Chadman et al., 2008; McFarlane et al., 2008; Moy et al., 2008; Yang et al., 2009, 2011a,c; Silverman et al., 2010a,b, 2011). The WT-HET cohort and Cohort 1 were tested between 10 and 16 weeks of age. Cohort 2 was tested at 6-7 weeks of age. Novel target mice were $129 /$ SvImJ mice between 8 and 16 weeks of age, of the same sex as the subjects. The apparatus was a rectangular, three-chambered box made of clear polycarbonate. Retractable doorways built into the two dividing walls controlled access to the side chambers. Number of entries and time spent in each chamber were automatically detected by photocells embedded in the doorways and tallied by the software. The test session began with a 10 min habituation session in the center chamber only, followed by a $10 \mathrm{~min}$ habituation to all three empty chambers. Lack of innate side preference was confirmed during the second 10 min habituation. The subject was then briefly confined to the center chamber while the clean novel object (an inverted stainless-steel wire pencil cup; Galaxy; KitchenPlus; http://www.kitchen-plus.com) was placed in one of the side chambers. A novel mouse previously habituated to the enclosure was placed in an identical wire cup located in the other side chamber. A disposable plastic drinking cup containing a lead weight was placed on the top of each inverted wire pencil cup to prevent the subject from climbing on top. The side containing the novel object and the novel mouse alternated between the left and right chambers across subjects. After both stimuli were positioned, the two side doors were simultaneously lifted and the subject was allowed access to all three chambers for $10 \mathrm{~min}$. Time spent in each chamber and entries into each chamber were automatically tallied. Time spent sniffing the novel object and time spent sniffing the novel mouse during the $10 \mathrm{~min}$ test session were later scored from video recording, by an observer using two stopwatches. The apparatus was cleaned with $70 \%$ ethanol and water between subjects. $129 \mathrm{~Sv} / \mathrm{ImJ}$ was used as the target novel mouse because this strain is generally inactive, passive, and does not exhibit aggressive behaviors toward subject mice. Using a minimally active partner is a strategy that allows all approaches to be initiated by the subject mouse only. Up to four subject mice were tested in the same room at the same time, using a high-throughput multiunit arrangement of the four test chambers.

Male-female social interaction test. The male-female reciprocal social interaction test was conducted as previously described (Bozdagi et al., 2010; Scattoni et al., 2011). Results of the WT-HET group were published in a previous report (Bozdagi et al., 2010). Cohort 1 was tested between 10 and 16 weeks of age, and Cohort 2 was tested at 9-10 weeks of age. All male subjects were sexually naive at the time of testing. Each freely moving male subject was paired with a freely moving unfamiliar estrus C57BL/6J female for $5 \mathrm{~min}$. A digital closed-circuit television camera (Panasonic) was positioned horizontally $30 \mathrm{~cm}$ from the cage. An ultrasonic microphone (Avisoft UltraSoundGate condenser microphone cap- sule CM15; Avisoft Bioacoustics) was mounted $20 \mathrm{~cm}$ above the cage. Sampling frequency for the microphone was $250 \mathrm{kHz}$, and the resolution was 16 bits. The entire apparatus was contained in a sound-attenuating environmental chamber (ENV-018V; MED Associates). The WT-HET group and Cohort 1 were tested under red light illumination (10 lux). To explore whether more pronounced genotype differences would manifest if the reciprocal social interaction test was conducted under a brighter lighting condition, Cohort 2 was tested under white light illumination (250 lux). Videos from the male subjects were subsequently scored by two investigators uninformed of genotypes. Social sniffing (sum of noseto-nose sniffing, nose-to-anogenital sniffing, and sniffing of other body regions) and exploratory activity were scored using Noldus Observer software (Noldus Information Technology) as previously described (Scattoni et al., 2011). Ultrasonic vocalization spectrograms were displayed using Avisoft software (Bozdagi et al., 2010). Ultrasonic calls were identified manually by two highly trained investigators blind to genotype. Summary statistics were calculated using Avisoft software. Interrater reliability was $95 \%$.

Female urinary pheromone-elicited scent marking and ultrasonic vocalizations. One week after the male-female social interaction test, male subjects of the WT-HET group and Cohort 1 were tested for scent marking behaviors and ultrasonic vocalizations in the presence of female urinary pheromones, as previously described (Roullet et al., 2011; Wöhr et al., 2011). Briefly, the test was conducted in the open-field arena and under red light illumination. To reduce background noise during ultrasonic vocalization recording, each open field was covered with a transparent Plexiglas lid equipped with ventilation holes. The floor of the open field was covered with a sheet of specialized drawing paper (Strathmore Drawing Paper Premium, recycled, microperforated, 400 series; Strathmore Artist Papers), which effectively absorbed drops of mouse urine. Each male subject was habituated to the paper-lined open-field arena for $60 \mathrm{~min}$, in the absence of female urinary odor. To reduce noveltyinduced stress during habituation, a small amount of home cage bedding was put in the corner of each open field. At the end of the habituation, each subject was transferred to a clean temporary holding cage. Home cage bedding and fecal deposits were removed from each open field. Scent marks deposited on the paper during habituation were visualized under ultraviolet light using an ultraviolet lamp (Sleeklook Super 18 " Black Light; eParty Unlimited). Visualized scent marks were outlined using a black pencil. Fifteen microliters of fresh urine from a novel estrous B6 female was then pipetted onto the center of the paper. The subject mouse was placed back into the open field for $5 \mathrm{~min}$. Scent marks deposited during the 5 min exposure to fresh female urinary pheromones were outlined with a blue colored pen. The open field was cleaned with $70 \%$ ethanol and water between subjects.

Juvenile reciprocal social interaction. Juvenile reciprocal social interactions were tested between postnatal days 21 and 25, immediately before pups were weaned from the mother. The test was conducted in the Noldus PhenoTyper Observer 3000 chamber $(25 \times 25 \times 35 \mathrm{~cm}$; Noldus $)$ as previously described (Yang et al., 2009, 2011b). The floor of the arena was covered with a $0.5 \mathrm{~cm}$ layer of clean bedding. Each subject mouse was singly housed in a clean cage for $1 \mathrm{~h}$ before the test. After this brief isolation period, the freely moving subject mouse and a freely moving age- and sex-matched B6 partner mouse were simultaneously placed in the arena and their interactions were videotaped for $10 \mathrm{~min}$. Social interactions were scored by a highly trained observer, using the Noldus Observer 5.0 software. Parameters of social behaviors included nose-to-nose sniff (sniffing the nose and snout region of the partner), front approach (moving toward the partner from a distance, in a head-on manner), follow (walking straight behind the partner, keeping pace with the one ahead), nose-to-anogenital sniff (sniffing the anogenital region of the partner), and push-crawl (pushing the head underneath the partner's body or squeezing between the wall/floor and the partner, and crawling over or under the partner's body are two similar behaviors, which were combined as a single parameter), and avoidance to approach (moving sideways quickly or turning away from the partner when being approached). In addition to social behaviors, nonsocial arena exploration (walking around the arena, rearing, or sniffing the wall) and bouts of self-grooming were scored as measures of exploratory activity and repet- 
itive behavior, respectively. All behaviors were analyzed for frequency of occurrence (i.e., number of bouts).

Developmental milestones. Cohorts 1 and 2 were tested in assays of developmental milestones every other day from postnatal day 2 to 14, as previously described (Chadman et al., 2008; Scattoni et al., 2008b). Parameters of physical developmental milestones were body weight, body and tail lengths, fur development, eye opening, pinna detachment, and incisor eruption. Parameters of behavioral developmental milestones were righting reflex, negative geotaxis, cliff aversion, forepaw grasping reflex, auditory startle, level screen, screen climbing, and bar holding.

Pup ultrasonic vocalizations. The WT-HET cohort and Cohort 1 were tested for separation-induced ultrasonic vocalizations (USVs) on postnatal days 4, 6, 8, and 11, as previously described (Chadman et al., 2008; Scattoni et al., 2008b). A total of 42 pups from 10 litters was tested in Bethesda, Maryland. A separate cohort of 27 pups was tested at Mount Sinai, on postnatal day 8 . The pup was gently removed from the nest and placed in a glass bowl $(10 \times 8 \times 8.5 \mathrm{~cm})$, which was covered by a $0.5 \mathrm{~cm}$ layer of fresh bedding. The bowl was immediately placed in a soundattenuating Styrofoam container, inside a sound-attenuating environmental chamber (ENV-018V; MED Associates). At the end of the 3 min recording session, each pup was weighed, its axillary temperature was taken (Microprobe digital thermometer with mouse probe; Stoelting), and it was returned to the nest. Room temperature was maintained at $23 \pm 1{ }^{\circ} \mathrm{C}$. Ultrasonic vocalizations were recorded by an Ultrasound $\mathrm{Mi}-$ crophone (Avisoft UltraSoundGate condenser microphone capsule CM16; Avisoft Bioacoustics) sensitive to frequencies of $10-180 \mathrm{kHz}$. The microphone was passed through a hole in the middle of the Styrofoam lid and affixed to it, leaving a distance of $\sim 20 \mathrm{~cm}$ between the microphone and the mouse. Ultrasonic calls were recorded using the Avisoft Recorder (version 3.4). Sampling rate was $250 \mathrm{kHz}$, format 16 bit. For acoustical analysis, recordings were transferred to Avisoft SASLab Pro (version 5.0) and a fast Fourier transformation (FFT) was conducted. Spectrograms were generated with an FFT length of 1024 points and a time window overlap of $50 \%$ ( $100 \%$ frame, Hamming window). The spectrogram was produced at a frequency resolution of $488 \mathrm{~Hz}$ and a time resolution of 1 ms. A lower cutoff frequency of $15 \mathrm{kHz}$ was used to reduce background noise outside the relevant frequency band to $0 \mathrm{~dB}$. Call detection was provided by an automatic threshold-based algorithm and a hold time mechanism (hold time, $0.01 \mathrm{~s}$ ). Three highly trained investigators, uninformed of the genotypes, manually scored total number of calls, average call duration, peak sound frequencies (frequencies with the highest sound pressure), and peak amplitude at the peak frequency (maximum of the spectrum). Concordance rate among the scorers was $>95 \%$. A separate cohort was tested at Mount Sinai School of Medicine, on postnatal day 8 only, in a 10 min session. Identical recording and scoring methods were used for experiments conducted at NIMH and Mount Sinai School of Medicine.

Olfactory habituation/dishabituation test. Evaluation of responses to nonsocial and social odors was conducted as previously described (Wrenn et al., 2004; Chadman et al., 2008; Yang and Crawley, 2009). Each subject mouse was tested in a clean empty mouse cage containing a thin layer of fresh pinewood bedding. Odor-saturated cotton-tipped swabs (6 inch length; Solon Manufacturing Company) were used to deliver odor stimuli. To reduce novelty-induced exploratory activities, each subject was first habituated for $45 \mathrm{~min}$ in the empty testing cage containing one clean dry cotton swab. The test consisted of 15 sequential 2 min trials: three presentations of plain tap water, three presentations of almond odor (prepared from almond extract; McCormick; 1:100 dilution), three presentations of banana odor (prepared from imitation banana flavor; McCormick; 1:100 dilution), three presentations of social odor from social cage 1, three presentations of social odor from social cage 2 . Water, almond odor, and banana odor stimuli were prepared by dipping the cotton tip briefly into the solution. Social odor stimuli were prepared by wiping a swab in a zigzag motion across a soiled cage of unfamiliar mice of the same sex. For each subject, one soiled cage of 129/SvImJ mice and one soiled cage of B6 mice were the sources of the two social odors. Time spent sniffing the swab was quantified with a stopwatch by an observer sitting $2 \mathrm{~m}$ away from the testing cage. Sniffing was scored when the nose was within $1 \mathrm{~cm}$ of the cotton swab. The intertrial interval was $\sim 1 \mathrm{~min}$.

Acoustic startle threshold and prepulse inhibition of acoustic startle. Acoustic startle and prepulse inhibition of acoustic startle were measured using the SR-Laboratory System (San Diego Instruments) as described previously (Holmes et al., 2001; Wrenn et al., 2004; Chadman et al., 2008; Silverman et al., 2011). Test sessions began by placing the mouse in the Plexiglas holding cylinder for a $5 \mathrm{~min}$ acclimation period. For the next 8 min, mice were presented with each of six trial types across six discrete blocks of trials, for a total of 36 trials. The intertrial interval was 10-20 s. One trial type measured the response to no stimulus (baseline movement). The other five trial types measured startle responses to $40 \mathrm{~ms}$ sound bursts of $80,90,100,110$, or $120 \mathrm{~dB}$. The six trial types were presented in pseudorandom order such that each trial type was presented once within a block of six trials. Startle amplitude was measured every 1 ms over a $65 \mathrm{~ms}$ period beginning at the onset of the startle stimulus. The maximum startle amplitude over this sampling period was taken as the dependent variable. Background noise level of $70 \mathrm{~dB}$ was maintained over the duration of the test session. For prepulse inhibition of acoustic startle, mice were presented with each of seven trial types across six discrete blocks of trials for a total of 42 trials, over $10.5 \mathrm{~min}$. The intertrial interval was $10-20 \mathrm{~s}$. One trial type measured the response to no stimulus (baseline movement) and another measured the startle response to a 40 $\mathrm{ms}, 110 \mathrm{~dB}$ sound burst. The other five trial types were acoustic prepulse stimulus plus acoustic startle stimulus trials. The seven trial types were presented in pseudorandom order such that each trial type was presented once within a block of seven trials. Prepulse stimuli were $20 \mathrm{~ms}$ tones of $74,78,82,86$, and $92 \mathrm{~dB}$ intensity, presented $100 \mathrm{~ms}$ before the $110 \mathrm{~dB}$ startle stimulus. Startle amplitude was measured every $1 \mathrm{~ms}$ over a $65 \mathrm{~ms}$ period, beginning at the onset of the startle stimulus. The maximum startle amplitude over this sampling period was taken as the dependent variable. A background noise level of $70 \mathrm{~dB}$ was maintained over the duration of the test session.

Hot-plate and tail flick pain sensitivity tests. Response to thermal stimulation of the feet and tail was measured as previously described (Wrenn et al., 2004; Chadman et al., 2008; Silverman et al., 2010a,c). For the hot-plate test, the mouse was placed on the arena surface, which was kept at a constant temperature of $55^{\circ} \mathrm{C}$ (IITC Life Science). Latency to first response, such as licking or shaking paws, was recorded. To prevent tissue damage, a cutoff latency of $30 \mathrm{~s}$ was applied. For the tail flick test, mice were gently restrained with the tail placed in the groove of the tail flick monitor (Columbus Instruments). An intense photobeam was directed at the tail. Latency for the mouse to move its tail out of the path of the beam was timed automatically by the apparatus. To prevent tissue damage, a cutoff latency of $10 \mathrm{~s}$ was applied.

Repetitive self-grooming. Mice were scored for spontaneous grooming behaviors when placed individually in a clean, empty mouse cage without bedding, using methods previously described (Yang et al., 2007; McFarlane et al., 2008). Each mouse was given a $10 \mathrm{~min}$ habituation period in the empty cage and then rated for $10 \mathrm{~min}$ for cumulative time spent grooming all body regions. The test session was videotaped and scored later by two trained observers uninformed of the genotypes. The interrater reliability was $>95 \%$.

Elevated plus-maze and light $\leftrightarrows$ dark exploration tests of anxiety-like behaviors. Cohort 2 was tested for anxiety-like behaviors in the elevated plus-maze test and the light $\leftrightarrows$ dark exploration test, using methods previously described (Crawley and Goodwin, 1980; Holmes et al., 2001; Bailey et al., 2007; Chadman et al., 2008; Yang et al., 2009). The elevated plus-maze consisted of two open arms $(30 \times 5 \mathrm{~cm})$ and two closed arms $(30 \times 5 \times 15 \mathrm{~cm})$ extending from a central area $(5 \times 5 \mathrm{~cm})$. Room illumination was $\sim 30$ lux. The test began by placing the subject mouse in the center, facing a closed arm. The mouse was allowed to freely explore the maze for $5 \mathrm{~min}$. Time spent in the open arms and closed arms, and number of entries into the open arms and closed arms, were scored by an investigator, using Observer software (Noldus Information Technology). The light $\leftrightarrows$ dark exploration test was conducted in an automated chamber (NIMH Research Services Branch, Bethesda, MD). The test began by placing the mouse in the light compartment facing away from the partition. The animal was allowed to freely explore the apparatus for 
$10 \mathrm{~min}$. Time spent in each compartment and number of transitions between the light (350 lux) and dark (3 lux) compartments were automatically recorded.

Morris water maze acquisition and reversal. Spatial learning and reversal learning were assessed in the Morris water maze using procedures and equipment as previously described (Miyakawa et al., 2001; Wrenn et al., 2004; Bailey et al., 2007; Chadman et al., 2008). The apparatus was a circular pool (120 cm diameter) filled $45 \mathrm{~cm}$ deep with tap water rendered opaque with the addition of nontoxic white paint (Crayola). Distal room cues were black-and-white cardboard patterns on the walls, $\sim 1 \mathrm{~m}$ from the circumference of the pool. Trials were videotaped and scored with WaterMaze video tracking software (Actimetrics). Acquisition training consisted of four trials a day for $\sim 5 \mathrm{~d}$. Each training trial began by lowering the mouse into the water close to the pool edge, in a quadrant that was either right of, left of, or opposite to, the target quadrant containing the platform. The start location for each trial was alternated in a semirandom order for each mouse. The hidden platform remained in the same quadrant for all trials during acquisition training for a given mouse, but varied across subject mice. Mice were allowed a maximum of $60 \mathrm{~s}$ to reach the platform. A mouse that failed to reach the platform in $60 \mathrm{~s}$ was guided to the platform by the experimenter. Mice were left on the platform for $15 \mathrm{~s}$ before being removed. After each trial, the subject was placed in a cage lined with absorbent paper towels and allowed to rest under an infrared heating lamp for $60 \mathrm{~s}$. Acquisition training continued for $5 \mathrm{~d}$, or until the $+/+$ control group reached criterion. Three hours after the completion of training on day 5 , the platform was removed and mice were tested in a $60 \mathrm{~s}$ probe trial, to confirm that their spatial learning was acquired by using distal environmental room cues. Parameters recorded during training days were latency to reach the platform, total distance traveled, swim speed, and thigmotaxis. Time spent in each quadrant and number of crossings over the trained platform location and over analogous locations in the other quadrants was used to analyze probe trial performance. Cohort 1 reversal training began $3 \mathrm{~d}$ after the completion of acquisition training. Cohort 2 reversal training began $35 \mathrm{~d}$ after the completion of acquisition training, to evaluate the robustness of the reversal phenotypes with different intervals after the initial training. In reversal training trials, the hidden platform was moved to the quadrant opposite to its location during acquisition training, for each mouse. Procedures for reversal training and probe trial were the same as in the initial acquisition phase.

Contextual and cued fear conditioning. Cohorts 1 and 2 were tested on standard delay fear conditioning as previously described (Paylor et al., 2001; Chadman et al., 2008). Training and conditioning tests took place in two identical chambers (MED Associates) that were calibrated to deliver identical footshocks. Each chamber was $30 \times 24 \times 21 \mathrm{~cm}$ with a clear polycarbonate front wall, two stainless side walls, and a white opaque back wall. The bottom of the chamber consisted of a removable grid floor with a waste pan underneath. When placed in the chamber, the grid floor connected with a circuit board for delivery of scrambled electric shock. Each conditioning chamber was inside a sound-attenuating environmental chamber. A camera mounted on the front door of the environmental chamber recorded test sessions, which were later scored automatically, using VideoFreeze software (MED Associates). For the training session, each chamber was illuminated with a white house light. An olfactory cue was added by dabbing a drop of imitation banana flavoring solution (1:100 dilution in water) on the metal tray beneath the grid floor. The mouse was placed in the test chamber and allowed to explore freely for $2 \mathrm{~min}$. A pure tone $(5 \mathrm{kHz}, 80 \mathrm{~dB})$, which served as the conditioned stimulus (CS), was played for $30 \mathrm{~s}$. During the last $2 \mathrm{~s}$ of the tone, a footshock $(0.5 \mathrm{~mA})$ was delivered as the unconditioned stimulus (US). Each mouse received three CS-US pairings, separated by $90 \mathrm{~s}$ intervals. After the last CS-US pairing, the mouse was left in the chamber for another $120 \mathrm{~s}$, during which freezing behavior was scored. The mouse was then returned to its home cage. Contextual conditioning was tested $24 \mathrm{~h}$ later in the same chamber, with the same illumination and olfactory cue present but without footshock. Each mouse was placed in the chamber for $5 \mathrm{~min}$, in the absence of CS and US, during which freezing was scored. The mouse was then returned to its home cage. Cued conditioning was conducted $48 \mathrm{~h}$ after training. Contextual cues were altered by covering the grid floor with a smooth white plastic sheet, inserting a piece of black plastic sheet bent to form a vaulted ceiling, using near infrared light instead of white light, and dabbing vanilla instead of banana odor on the floor. The session consisted of a $3 \mathrm{~min}$ free exploration period followed by $3 \mathrm{~min}$ of the identical CS tone $(5 \mathrm{kHz}, 80 \mathrm{~dB})$. Freezing was scored during both 3 min segments. The mouse was then returned to its home cage. The chamber was thoroughly cleaned of odors between sessions, using $70 \%$ ethanol and water.

Novel object recognition. The novel object recognition test was conducted with Cohort 2 mice in the open-field arena, using methods previously described (Bevins and Besheer, 2006). The experiment consisted of two habituation sessions, a $10 \mathrm{~min}$ familiarization session, and a $5 \mathrm{~min}$ recognition test. On day 1 , each subject was habituated to a clean empty open-field arena for $30 \mathrm{~min}$. Twenty-four hours later, each subject was returned to the open-field arena for a second habituation phase, this time for $10 \mathrm{~min}$. The mouse was then removed from the open field and placed in a clean temporary holding cage for $\sim 2 \mathrm{~min}$. Two identical objects were placed in the arena. Each subject was returned to the open field in which it had been habituated, and allowed to explore freely for $10 \mathrm{~min}$. After the familiarization session, subjects were returned to their holding cages, which were transferred from the testing room to a nearby holding area. The open field was cleaned with $70 \%$ ethanol and let dry. One clean familiar object and one clean novel object were placed in the arena, where the two identical objects had been located during in the familiarization phase. One hour after the familiarization session, each subject was returned to its open field for a $5 \mathrm{~min}$ recognition test, during which time it was allowed to freely explore the familiar object and the novel object. The familiarization session and the recognition test were videotaped and subsequently scored by two highly trained investigators, uninformed of genotype, whose interrater reliability was $\geq 95 \%$. Object investigation was defined as time spent sniffing the object when the nose was oriented toward the object and the nose-object distance was $2 \mathrm{~cm}$ or less. Recognition memory was defined as spending significantly more time sniffing the novel object than the familiar object. Total time spent sniffing both objects was used as a measure of general exploration. Time spent sniffing two identical objects during the familiarization phase confirmed the lack of an innate side bias.

Rotarod motor learning. Motor learning was assessed using a mouse accelerating rotarod (Ugo Basile). Mice were placed on the rotating drum that accelerated from 4 to $40 \mathrm{rpm}$ over $5 \mathrm{~min}$. Cohort 1 was tested for three trials a day, for 2 consecutive days. Cohorts 2 and 3 were tested for two trials a day, for 3 consecutive days. The intertrial interval was $1 \mathrm{~h}$ for all three cohorts. Rotarod scores were scored for latency to either fall or ride the rod around for all three cohorts. Cohort 3 was also scored for latency to fall, a more stringent criterion.

Statistical analyses. Shank $3+/+,+/-$, and $-/-$ littermates were compared for each behavioral task. One-way ANOVA was used to detect genotype differences in electrophysiological parameters, body weight, body temperature, wire hang, pain sensitivity, juvenile social interactions, elevated plus-maze, light $\leftrightarrows$ dark exploration, open-field exploratory activities, male-female social interactions, male scent marking, repetitive self-grooming, and fear conditioning. Scheffé's test was used for post hoc comparisons following significant ANOVA results. Repeatedmeasures ANOVA was used to analyze developmental milestones and pup vocalizations across days, acoustic startle threshold, prepulse inhibition, rotarod motor learning, olfactory habituation/dishabituation, novel object recognition, and Morris water maze. Newman-Keuls or Tukey's post hoc tests were used for post hoc comparisons following significant repeatedmeasures ANOVA results. For the automated three-chambered social approach test, repeated-measures ANOVA was used to compare time spent in the two side chambers, with the factor of chamber side (novel mouse side vs novel object side). Time spent sniffing the novel mouse versus the novel object was similarly analyzed. Time spent in the center chamber is included on the graphs for illustrative purposes, but not included in the statistical analysis. 


\section{Results}

Electrophysiology

The role of Shank3 in regulating glutamatergic synaptic transmission was studied in hippocampal slices from Shank3 mutant mice. The slope of fEPSPs were plotted against stimulus intensity in slices from wild-type littermate controls $(+/+)$, Shank3 heterozygotes (+/-), and Shank3 homozygous null mutants $(-/-), N=9$ per genotype, $2-3$ slices per mouse. The mean slope of the input-output curves is shown in Figure 1. Input-output curves demonstrated a decrease in fEPSP slope across all stimulation intensities in both Shank $3+1-$ and $-1-$ mice, indicating a significant reduction in basal transmission (average slope of input-output function: $+/+, 1.38 \pm 0.3 ;+/-, 1.07 \pm 0.2$; $\left.-/-, 0.91 \pm 0.2 ; F_{(2,21)}=7.30, p<0.01\right)$. In the $+/+$ control group, fEPSP slope recorded in area CA1 significantly increased over baseline after theta burst stimulation (TBS) and was sustained for at least $60 \mathrm{~min}(154.7 \pm 2.9 \%$ of baseline at $60 \mathrm{~min} ; 159.3 \pm 2.6 \%$ at $40 \mathrm{~min}$ postTBS). In Shank3 - / - mice, the initial potentiation was significantly lower and decayed rapidly to baseline by $40 \mathrm{~min}$ $(101.9 \pm 2.4 \%$ at $40 \mathrm{~min}$ post-TBS; $N=$ $4-7$ mice per genotype; $\left.F_{(2,14)}=85.2, p<0.001\right)$. Shank3 $+/-$ mice also showed reduced TBS-induced LTP but normal initial potentiation. NMDA receptor-dependent LTD induced by lowfrequency stimulation was not significantly different across genotypes (field EPSP: $82.6 \pm 1.35 \%$ of baseline in $+/+, 82.5 \pm 1.9 \%$ in $+/-$, and $80.6 \pm 6 \%$ in $-/-$, measured 60 min after LFS; mean $\pm \mathrm{SD} ; N=3$ mice per group; $F_{(2,11)}=0.34$, NS). Following paired-pulse LFS, which induces protein synthesis-dependent LTD, the maintenance of LTD was not significantly different among Shank3 $+/+,+/-$, and $-/-$ mice, over the 90 min time course as well $(84.2 \pm 6.08 \%$ in $+/+, 81.9 \pm 7.1 \%$ in $+/-$, and $90.2 \pm 5.8 \%$ of baseline in $-/-$, measured 90 min after PP-LFS; mean $\pm \mathrm{SD} ; N=4$ mice per group; $\left.F_{(2,11)}=0.36, \mathrm{NS}\right)$.

\section{General health and neurological reflexes}

Adult Shank3 mice were evaluated for general health and neurological reflexes between 10 and 16 weeks of age. Similar results were obtained in three cohorts. Representative data from Cohort 1 are shown in Table 1. Mice from Cohort 2 were used for one parameter, grip strength. The three genotypes scored similarly on measures of body weight, neurological reflexes, motor functions including open-field activity, wire hang and gait, and responsivity to handling. No balding patches were observed in mice evaluated during this age range. Observations of home cage behaviors revealed no abnormalities in general activity, group huddling, and nesting. No excessive aggressive behaviors were observed in adult males. Nursing females showed normal maternal behaviors. Average litter size was 7.2 pups (range of 3-11). Bald patches were occasionally observed in $+/-$, especially in mice older than 10 months. Forelimb grip strength did not differ significantly across genotypes in males $\left(F_{(2,32)}=0.065\right.$; NS) (Table 1 ) or females $\left(F_{(2,27)}=2.53\right.$; NS) (data not shown). Footprint analysis revealed no significant genotype differences in gait, as measured by fore-
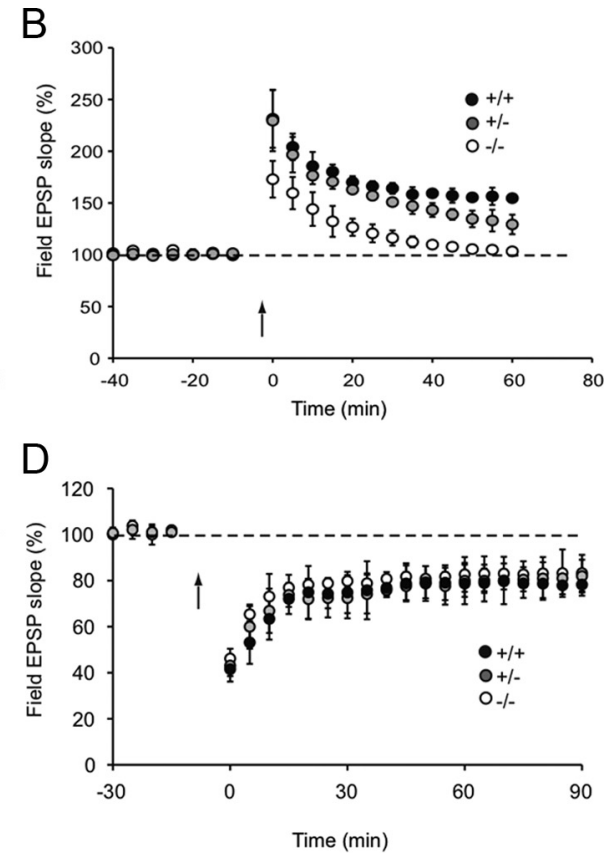

B

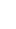

Figure 1. Shank3 homozygous mice exibited impairment in synaptic transmission, induction, and maintenance of long-term potentiation. $\boldsymbol{A}$, Input- output curve, representing the relationship between stimulus intensity and the size of the fEPSP slope,

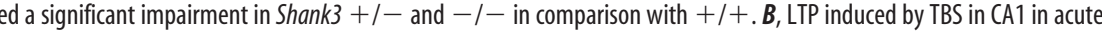
hippocampal slices ( $N=4-7 /$ genotype) was significantly impaired in slices taken from the Shank3 $+/-$ and $-/-$ mice. $C, D$, Field recordings in CA1 in acute slices from Shank3 $+1+$ and $+/-$ and $-1-$ mice showed no differences between genotypes in NMDA receptor-dependent (C) or protein synthesis-dependent LTD (D). Error bars indicate SD.

paw width $\left(F_{(2,24)}=0.73\right.$; NS), hindpaw width $\left(F_{(2,24)}=0.05\right.$; NS), and stride length $\left(F_{(2,24)}=2.54\right.$; NS). In Cohort 1 , openfield exploratory locomotion did not differ significantly across genotypes on measures of total distance traveled $\left(F_{(2,40)}=\right.$ 1.64 ; NS), vertical activity $\left(F_{(2,40)}=0.01 ; \mathrm{NS}\right)$, and center time $\left(F_{(2,40)}=0.90 ; \mathrm{NS}\right)$. A significant genotype effect was found in horizontal activity $\left(F_{(2,40)}=4.13 ; p<0.05\right)$, with $-/-$ showing lower levels of horizontal activity than $+/+(p<0.05)$ (Table 1). In females (data not shown), no significant genotype differences were found on total distance traveled $\left(F_{(2,27)}=1.96\right.$; NS $)$, horizontal activity $\left(F_{(2,27)}=1.46\right.$; NS $)$, vertical activity $\left(F_{(2,27)}=0.96 ; \mathrm{NS}\right)$, and center time $\left(F_{(2,27)}=\right.$ 0.94; NS). In Cohort 2 (data not shown), open-field exploratory locomotion in a $30 \mathrm{~min}$ session was somewhat lower in mutants compared with wild-type littermates on some parameters. In Cohort 2 males, small but significant genotype differences were found in total distance traveled $\left(F_{(2,33)}=3.57 ; p<\right.$ $0.05)$ and horizontal activity $\left(F_{(2,33)}=5.63 ; p<0.05\right)$. Post hoc comparisons revealed that $-/-$ exhibited lower levels of horizontal activity than $+/+$ controls $(p<0.05)$. No significant genotype differences were found in vertical activity $\left(F_{(2,33)}=\right.$ 1.96 ; NS) and center time $\left(F_{(2,33)}=2.99\right.$; NS). In Cohort 2 females, significant genotype differences were found in total distance traveled $\left(F_{(2,34)}=3.58 ; p<0.05\right)$, horizontal activity $\left(F_{(2,34)}=6.90 ; p<01\right)$, and vertical activity $\left(F_{(2,34)}=6.20 ; p<\right.$ $0.01)$. Post hoc comparisons revealed that $+/-$ females exhibited higher levels of horizontal activity $(p<0.05)$ and vertical activity $(p<0.01)$ compared with $+/+$. Center time did not differ significantly across genotypes $\left(F_{(2,34)}=1.47\right.$; NS). While reasons for the discrepancy in open-field results between cohorts remain unknown, noise from construction of a nearby building occurred sporadically during some of the days when open-field testing was conducted in Cohort 2. 
Table 1. General health, reflexes, sensory abilities, motor functions

\begin{tabular}{|c|c|c|c|}
\hline Genotypes & $+/+(N=19)$ & $+1-(N=27)$ & $-1-(N=22)$ \\
\hline Fur condition (3 point scale) & 2 & 2 & 2 \\
\hline Bald patches (\%) & 5.2 & 0 & 0 \\
\hline Missing whiskers (\%) & 0 & 0 & 0 \\
\hline Piloerection (\%) & 3.7 & 3.7 & 22.7 \\
\hline Body tone (3 point scale) & 2 & 2 & 2 \\
\hline Limb tone (3 point scale) & 2 & 2 & 2 \\
\hline Physical abnormalities (\%) & 0 & 0 & 0 \\
\hline Body weight (g) males & $26.8 \pm 0.85$ & $28.7 \pm 0.65$ & $27.2 \pm 0.92$ \\
\hline Body weight (g) females & $21.2 \pm 0.36$ & $21.7 \pm 0.32$ & $20.7 \pm 0.45$ \\
\hline Body temperature $\left({ }^{\circ} \mathrm{C}\right)$ & $32.3 \pm 0.31$ & $32.5 \pm 0.29$ & $33.0 \pm 0.32$ \\
\hline \multicolumn{4}{|l|}{ Empty cage behavior } \\
\hline Transfer freezing (\%) & 5.3 & 0 & 13.6 \\
\hline Wild running (\%) & 0 & 0 & 0 \\
\hline Stereotypies (\%) & 0 & 0 & 0 \\
\hline Exploration (3 point scale) & 2 & 2 & 2 \\
\hline \multicolumn{4}{|l|}{ Motoric abilities } \\
\hline Trunk curl (\%) & 94.7 & 96.3 & 100 \\
\hline Wire hang (latency) (s) & $54.2 \pm 5.78$ & $58.2 \pm 1.82$ & $52.8 \pm 4.80$ \\
\hline \multicolumn{4}{|l|}{ Reflexes } \\
\hline Forepaw reach (\%) & 100 & 100 & 100 \\
\hline Righting reflex (\%) & 100 & 100 & 95.5 \\
\hline Corneal (\%) & 100 & 100 & 100 \\
\hline Pinna (\%) & 100 & 100 & 100 \\
\hline Vibrissae (\%) & 100 & 100 & 100 \\
\hline \multicolumn{4}{|l|}{ Reactivity } \\
\hline Auditory startle (\%) & 94.7 & 100 & 95.5 \\
\hline Struggle (\%) & 31.6 & 33.3 & 31.8 \\
\hline Dowel biting (\%) & $0.58 \pm 0.16$ & $0.63 \pm 0.12$ & $0.68 \pm 0.17$ \\
\hline \multirow[t]{2}{*}{ Grip strength } & $N=9$ & $N=12$ & $N=14$ \\
\hline & $108.4 \pm 4.8$ & $109.3 \pm 2.1$ & $107.1 \pm 3.6$ \\
\hline Open-field exploration & $N=11$ & $N=15$ & $N=17$ \\
\hline Total distance & $1646.6 \pm 153.0$ & $1512.7 \pm 99.0$ & $1371.6 \pm 78.1$ \\
\hline Horizontal activity & $3133.5 \pm 207.9$ & $2994.5 \pm 128.8$ & $2561.1 \pm 127.3^{*}$ \\
\hline Vertical activity & $104.2 \pm 13.3$ & $101.6 \pm 10.7$ & $102.5 \pm 10.7$ \\
\hline Center time (s) & $89.6 \pm 7.6$ & $100.2 \pm 7.7$ & $106.8 \pm 9.6$ \\
\hline Foot print test & $N=11$ & $N=11$ & $N=9$ \\
\hline Forepaw width & $1.43 \pm 0.11$ & $1.58 \pm 0.08$ & $1.44 \pm 0.12$ \\
\hline Hindpaw width & $2.35 \pm 0.14$ & $2.39 \pm 0.12$ & $2.39 \pm 0.08$ \\
\hline Stride length & $6.97 \pm 0.17$ & $6.65 \pm 0.19$ & $7.55 \pm 0.19$ \\
\hline
\end{tabular}

Normal general health, neurological reflexes, grip strength, locomotor activities, and gait functions were seen in adults of all genotypes of Shank3 mice. Data in Table 1 display the absence of genotype differences in general health measures for Cohort 1 , with the exception of grip strength. Similarly, no genotype differences were detected across the three genotypes on measures of general health and neurological reflexes in Cohort 2, or in either genotype of the WT-HET cohort. Cohort 2 and the WT-HET cohort were not tested for footprint gait. Genotype differences were found on several measures of open field locomotor activity in Cohort 2 (see Results for $F$ and $p$ values). ${ }^{*} p<0.05$ compared with $+/+$.

Adult social approach in the automated three-chambered task Normal sociability was found in all three cohorts of Shank3 mice of all genotypes. Figure 2 displays the significant sociability detected in adult Shank3 mice of Cohort 1. In both sexes, significantly more time was spent in the chamber containing the novel mouse than in the chamber containing the novel object, and more time was spent sniffing the novel mouse than the novel object: chamber time: $A$, male $+/+, F_{(1,17)}=42.88, p<0.001$; male $+/-, F_{(1,20)}=6.00, p<0.01 ;$ male $-/-, F_{(1,20)}=5.76, p<$ 0.05 ; $C$, female $+/+, F_{(1,9)}=10.32, p<0.01$; female $+/-$, $F_{(1,16)}=33.00, p<0.001$; female $-1-, F_{(1,10)}=36.01, p<0.001$; sniff time: $B$, male $+/+, F_{(1,17)}=33.56, p<0.001$; male $+/-$, $F_{(1,19)}=73.45, p<0.001 ;$ male $-1-, F_{(1,20)}=52.65, p<0.001$; $D$, female $+/+, F_{(1,9)}=106.53, p<0.001$; female $+/-, F_{(1,16)}=$ 83.86, $p<0.001$; female $-/-, F_{(1,10)}=74.55, p<0.001$. Similarly, all three genotypes of Cohort 2 displayed normal sociability (data not shown): chamber time: male $+/+, F_{(1,10)}=82.00, p<$ 0.001 ; male $+/-, F_{(1,11)}=22.11, p<0.001$; male $-/-, F_{(1,10)}=$ 26.38, $p<0.001$; female $+/+, F_{(1,9)}=7.60, p<0.05$; female
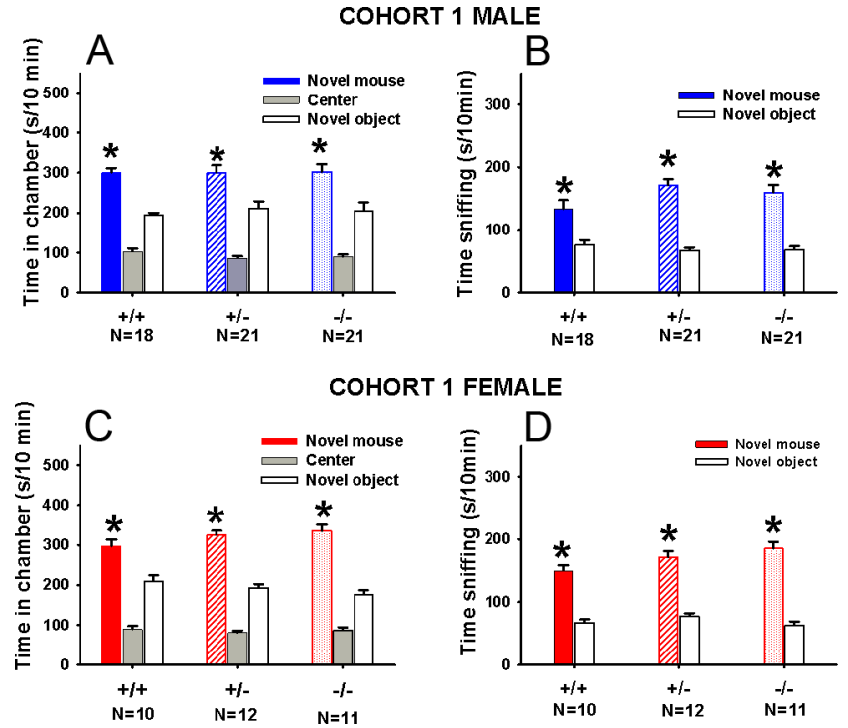

Figure 2. Normal sociability in Shank3 mice tested in the automated three-chambered social approach task. Adult male Shank3 $+/+,+1-,-1-$ and adult female Shank3 + / + $+/-,-I-$ all showed significant sociability, spending more time in the chamber containing the novel mouse than in the chamber containing the novel object $(\boldsymbol{A}, \boldsymbol{C})$. Similarly, all genotypes displayed significantly more time sniffing the novel mouse than the novel object $(\boldsymbol{B}, \boldsymbol{D}) .{ }^{*} p<$ 0.05 , comparison between novel mouse and novel object. Error bars indicate SEM.

$+/-, F_{(1,10)}=30.00, p<0.001$; female $-/-, F_{(1,15)}=14.33, p<$ 0.01 ; sniff time: male $+/+, F_{(1,10)}=80.00, p<0.001$; male $+/-$, $F_{(1,11)}=60.22, p<0.001 ;$ male $-/-, F_{(1,10)}=55.180 .00, p<$ 0.001 ; female $+/+, F_{(1,9)}=8.60, p<0.05$; female $+/-, F_{(1,10)}=$ $30.44 p<0.001$; female $-/-, F_{(1,15)}=48.7, p<0.001$. Similar sociability was seen in the previously published WT-HET group (data not shown): chamber time: male $+/+, F_{(1,13)}=8.50, p<$ 0.01 ; male $+/-, F_{(1,11)}=44.72, p<0.001$; female $+/+, F_{(1,7)}=$ $8.13, p<0.05$; female $+/-, F_{(1,12)}=31.32, p<0.001$; sniff time: male $+/+, F_{(1,13)}=63.00, p<0.001$; male $+/-, F_{(1,11)}=45.82$, $p<0.001$; female $+/+, F_{(1,7)}=8.97, p<0.05$; female $+/-$, $F_{(1,12)}=50.25, p<0.001$.

\section{Adult male-female social interaction}

Figure 3 shows duration of total social sniffing and number of ultrasonic vocalizations in male Shank3 subjects paired with unfamiliar estrous B6 females in a 5 min social interaction test. In Cohort 1 , minor trends were seen for male $+/-$ and $-/-$ to show less total social sniffing (Fig. $3 A ; F_{(2,41)}=1.55, p=0.23$, NS) and fewer ultrasonic vocalizations (Fig. $3 B ; F_{(2,41)}=1.50$, $p=0.24$, NS) than $+1+$ controls. In Cohort 2 , no trends or significant genotype differences were seen for total social sniffing (Fig. 3C; $F_{(2,41)}=0.11$; NS) or ultrasonic vocalizations (Fig. 3D; $F_{(2,41)}=0.47$; NS).

\section{Ultrasonic vocalizations, scent marking, and open-field} activity by males in the presence of female urine

Figure 4 shows scent marking behaviors and ultrasonic vocalizations in Cohort 1 males in response to $15 \mu$ l of female urine deposited in the center of an open-field arena. During the $5 \mathrm{~min}$ urine exposure, no significant genotypes differences were found in number of ultrasonic vocalizations $\left(F_{(2,36)}=1.04\right.$; NS $)(A)$ and number of scent marks deposited in the open field $\left(F_{(2,36)}=0.81\right.$; NS) (C). A significant genotype effect was found in total distance traveled $\left(F_{(2,36)}=4.02 ; p<0.05\right)(D)$. Post hoc analysis revealed that total distance traveled was shorter in $-/-$ compared with 

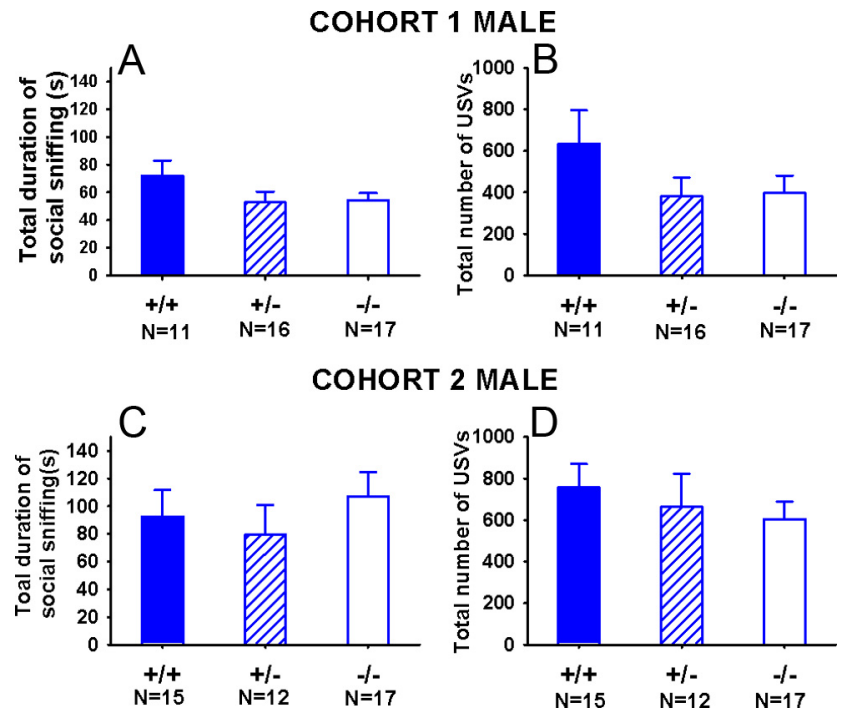

Figure 3. Adult reciprocal social interactions between male Shank3 and female B6 in freely moving dyads. In a 5 min test session, no significant genotype differences were found on measures of social interactions (scored as cumulative seconds spent by the male subject in sniffing the nose, anogenital, and other body regions of an unfamiliar adult estrus B6 female mouse). $\boldsymbol{A}$, Cohort 1. $\boldsymbol{C}$, Cohort 2. Number of ultrasonic vocalizations emitted during the social interaction test session in Cohort $1(\boldsymbol{B})$ and Cohort $2(\boldsymbol{D})$ show a nonsignificant trend toward $+/-$ and $-/$ - emitting lower levels USVs during social interactions than $+/+$ littermates. Error bars indicate SEM.
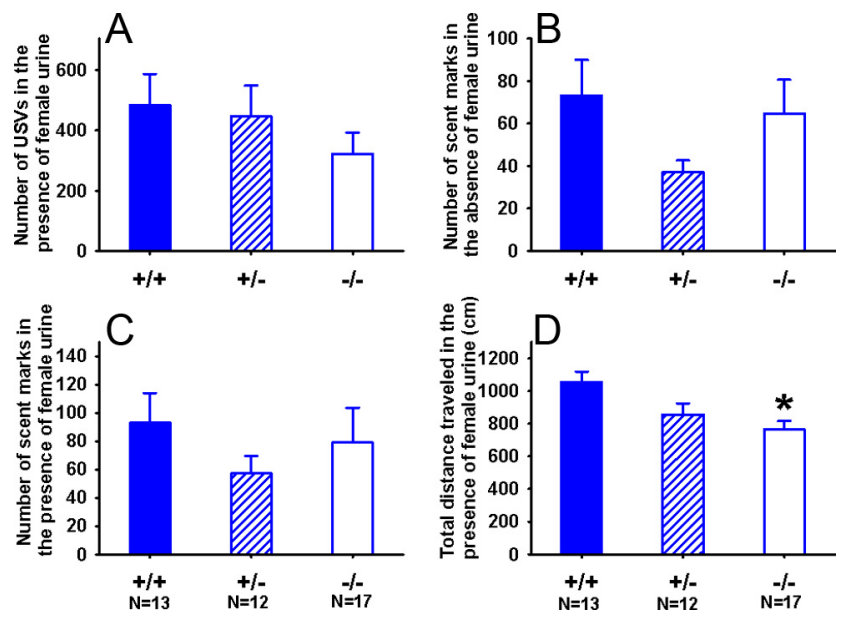

Figure 4. Adult scent marking and open-field activity in the presence of female urine. Behavioral and ultrasonic vocalization responses to female urinary pheromones in male Shank3 mice. No genotype differences were found in number of USVs emitted in the presence of female urine $(\boldsymbol{A})$, number of scent marks left in the arena over a $60 \mathrm{~min}$ acclimation period, before the introduction of female urine $(\boldsymbol{B})$, total number of scent marks left in the arena after the acclimation period and a 5 min exposure to a drop female urine $(\boldsymbol{C})$. D , Total distance traveled during the 5 min test was lower in $-/-$ males than in $+/+$ males. $+/+, N=13 ;+/-, N=12$; $-/-, N=17 .{ }^{*} p<0.05$ versus $+/+$. Error bars indicate SEM.

$+/+$ during urine exposure $(p<0.05)$. During the 60 min habituation period before the introduction of the female urine, no significant genotype differences were found in number of scent marks deposited in the clean open field $\left(F_{(2,36)}=2.51\right.$; NS) $(B)$. In the WT-HET cohort (data not shown), male $+/-$ emitted significantly fewer ultrasonic vocalizations than $+/+$, in the presence of female urinary pheromone $\left(F_{(1,24)}=4.37 ; p<0.05\right)$. No significant genotypes differences were found in the number of scent marks deposited in the open field during the 5 min urine exposure $\left(F_{(1,19)}=2.40\right.$; NS). The effect of genotype was not significant for total distance traveled in the open field during female urine exposure $\left(F_{(1,19)}=0.13\right.$; NS). During the $60 \mathrm{~min}$ of habituation period in the empty open field, Shank3 $+/-$ males deposited fewer scent marks than $+/+$ controls $\left(F_{(1,19)}=4.58\right.$; $p<0.05)$. These results indicate a partial reduction in responses to social olfactory cues, whose significance was inconsistent across cohorts.

\section{Juvenile reciprocal social interactions}

Figure 5 shows results of reciprocal social interactions in three cohorts of Shank3 juveniles. In the WT-HET cohort, deficits were found on some but not all parameters. Shank3 +/- juveniles paired with B6 partners were lower on some parameters compared with $+/+$. Female $+/-$ showed significantly fewer bouts of nose-to-anogenital sniffing $\left(F_{(1,26)}=4.78 ; p<0.05\right)(D)$, following $\left(F_{(1,26)}=8.49 ; p<0.01\right)(E)$, and push-crawls $\left(F_{(1,26)}=4.49 ; p<0.05\right)(F)$, compared with $+/+$ controls. No significant differences were found in nose-to-nose $\operatorname{sniff}\left(F_{(1,26)}=\right.$ 0.27 ; NS) $(A)$, front approach $\left(F_{(1,26)}=0.07\right.$; NS) $(B)$, arena exploration $\left(F_{(1,26)}=1.04\right.$; NS) $(G)$, and bouts of self-grooming $\left(F_{(1,26)}=1.86\right.$; NS $)(H)$. Males showed no significant genotype differences on nose-to-nose sniff $\left(F_{(1,26)}=0.74\right.$; NS), front approach $\left(F_{(1,26)}=0.65 ; \mathrm{NS}\right)$, avoidance when approached $\left(F_{(1,26)}\right.$ $=2.95 ; \mathrm{NS})$, nose-to-anogenitial sniff $\left(F_{(1,26)}=0.00 ; \mathrm{NS}\right)$, following $\left(F_{(1,26)}=1.06\right.$; NS), push-crawl $\left(F_{(1,26)}=0.80\right.$; NS), arena exploration $\left(F_{(1,26)}=1.60\right.$; NS), and bouts of self-grooming $\left(F_{(1,26)}=0.40 ; \mathrm{NS}\right)$. In Cohort 1 , significant genotype differences were found in males, on nose-to-nose sniff $\left(F_{(2,46)}=3.50 ; p<\right.$ $0.05)(I)$, front approach $\left(F_{(2,46)}=11.30 ; p<0.01\right)(J)$, following $\left(F_{(2,46)}=12.76 ; p<0.01\right)(M)$, and push-crawl $\left(F_{(2,46)}=3.67\right.$; $p<0.05)(N)$. Post hoc comparisons with Scheffé's test indicated that the significant differences were between $+/-$ and $+/+$ on each of these parameters $(p<0.05)$, and between $-/-$ and $+/+$ on following $(p<0.01)$. Trends for genotype differences were also seen in avoidance when approached $\left(F_{(2,46)}=2.95 ; \mathrm{NS}\right)(K)$ and nose-to-anogenitial sniff $\left(F_{(2,46)}=1.88\right.$; NS $)(L)$. No significant genotype differences were found in the nonsocial parameters: arena exploration $\left(F_{(2,46)}=0.21\right.$; NS) $(O)$ and bouts of self-grooming $\left(F_{(2,46)}=0.06 ; \mathrm{NS}\right)(P)$. In females, no significant genotype differences were found on any parameters, including nose-to-nose $\operatorname{sniff}\left(F_{(2,32)}=1.45\right.$; NS), front approach $\left(F_{(2,32)}=\right.$ 2.92 ; NS), avoidance when approached $\left(F_{(2,32)}=1.54\right.$; NS), anogenital sniff $\left(F_{(2,32)}=0.11\right.$; NS), following $\left(F_{(2,32)}=1.11\right.$; NS), push-crawl $\left(F_{(2,32)}=1.28 ; \mathrm{NS}\right)$, arena exploration $\left(F_{(2,32)}=0.47\right.$; $\mathrm{NS})$, and bouts of self-grooming $\left(F_{(2,32)}=0.52\right.$; NS). In Cohort 2, significant genotype differences were found in males, on nose-tonose sniff $\left(F_{(2,35)}=3.76 ; p<0.05\right)(Q)$, avoidance when approached $\left(F_{(2,35)}=6.82 ; p<0.01\right)(S)$, push-crawl $\left(F_{(2,35)}=\right.$ $4.93 ; p<0.01)(V)$, and arena exploration $\left(F_{(2,35)}=8.72 ; p<\right.$ $0.01)(W)$. Compared with $+/+$ males, $-/-$ males exhibited significantly fewer bouts of nose-to-nose sniffs $(p<0.05)$, more avoidances $(p<0.01)$, and fewer push-crawls $(p<0.05) .+1-$ and $-/-$ exhibited less arena exploration than $+/+$ controls ( $p<0.01$ for each comparison). Genotype differences were not significant for front approach $\left(F_{(2,35)}=0.52\right.$; NS) $(R)$, nose-toanogenitial sniff $\left(F_{(2,35)}=1.24\right.$; NS) $(T)$, following $\left(F_{(2,35)}=\right.$ 0.25 ; NS) $(U)$, and bouts of self-grooming $\left(F_{(2,35)}=0.27\right.$; NS) $(X)$. Females showed minimal genotype differences in juvenile social interactions. No significant genotype effects were found in bouts of nose-to-nose sniff $\left(F_{(2,30)}=0.73\right.$; NS), front approach $\left(F_{(2,30)}=2.62 ; \mathrm{NS}\right)$, avoidance to approach $\left(F_{(2,30)}=0.82 ; \mathrm{NS}\right)$, following $\left(F_{(2,30)}=1.61\right.$; NS), push-crawl $\left(F_{(2,30)}=2.26\right.$; NS), arena exploration $\left(F_{(2,30)}=0.38 ; \mathrm{NS}\right)$, and self-grooming 
WT-HET COHORT
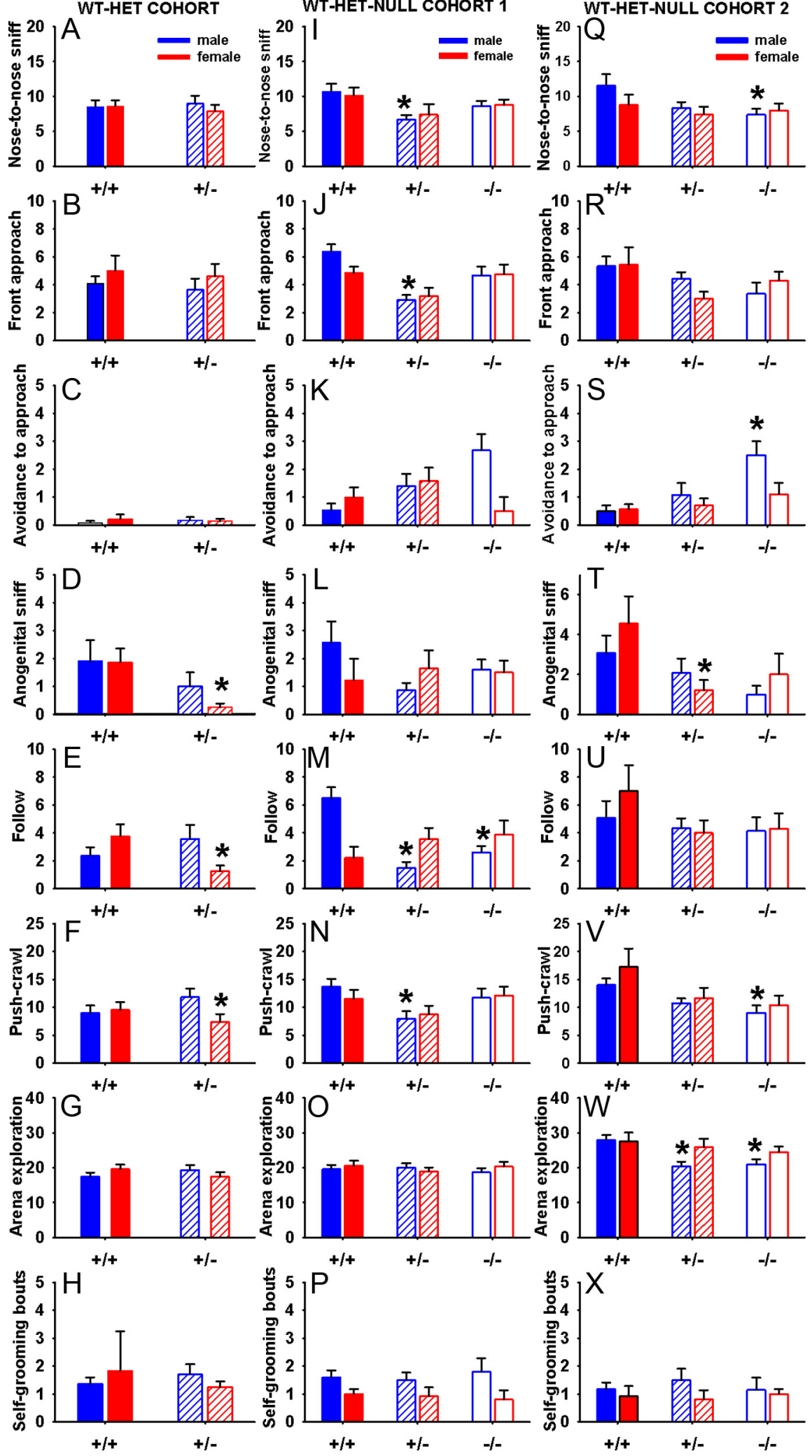

Figure 5. Juvenile reciprocal social interaction behaviors in Shank3 mice tested between age day 21 and day 25. Each subject mouse was paired with an unfamiliar B6 partner of the same sex for a 10 min test in a Noldus Phenotyper arena. Each subject mouse was paired with an unfamiliar male B6 partner for a $10 \mathrm{~min}$ test in a Noldus Phenotyper arena. In the WT-HET cohort, no genotype differences were found in males on any measures $(\boldsymbol{A}-\boldsymbol{H})$. In females, $+/-$ exhibited fewer bouts of anogenital sniffing $(\boldsymbol{D})$, following $(\boldsymbol{E})$, and push-crawl $(\boldsymbol{F})$, compared with $+/+$ controls. In Cohort 1, significant genotype differences were found in males, with $+/-$ exhibiting significantly fewer bouts of nose-to-nose sniffing $(\boldsymbol{I})$, front approach $(\boldsymbol{J})$, and push-crawl $(\boldsymbol{N})$, compared with $+/+$ controls, and both $+/-$ and $-/-$ exhibiting fewer bouts of following $(\boldsymbol{M})$ than $+/+$ controls. No significant genotype differences were found in females on any measures $(\boldsymbol{I}-\boldsymbol{P})$. In Cohort 2, significant genotype differences were
$\left(F_{(2,30)}=0.10 ; \mathrm{NS}\right)$. A significant genotype effect was found in nose-toanogenital sniff $\left(F_{(2,30)}=3.40 ; p<0.05\right)$. However, post hoc comparisons did not reveal significant differences among the three genotypes on this measure. Together, these results show a profile of reduced juvenile reciprocal social interactions in Shank3 null and heterozygous mutant males on some parameters. In contrast, females displayed comparatively normal juvenile reciprocal social interactions.

\section{Developmental milestones and pup} ultrasonic vocalizations

Figure 6 shows normal early physical development and separation-induced ultrasonic vocalizations in Shank3 pups of Cohort 1. No significant genotypes differences were detected on measures of early developmental milestones, including body weight $\left(F_{(2,55)}=0.34\right.$; NS) $(A)$, body length $\left(F_{(2,55)}=0.73\right.$; NS) $(B)$, righting reflex $\left(F_{(2,55)}=0.36 ; \mathrm{NS}\right)(C)$, pinna detachment $\left(F_{(2,55)}=0.21 ; \mathrm{NS}\right)(D)$, incisor eruption $\left(F_{(2,55)}=0.76 ; \mathrm{NS}\right)(E)$, and eye opening $\left(F_{(2,22)}=0.74\right.$; NS $)(F)$. Similar results were found in the WT-HET cohort (data not shown). No significant genotypes differences were detected on measures of early developmental milestones, including body weight $\left(F_{(1,22)}=1.08\right.$; NS), body length $\left(F_{(1,22)}=0.003\right.$; NS), righting reflex $\left(F_{(1,22)}=52\right.$; NS), pinna detachment $\left(F_{(1,22)}=0.18\right.$; NS), incisor eruption $\left(F_{(1,22)}=1.29\right.$; NS), and eye opening $\left(F_{(1,22)}=1.88\right.$; NS). Separationinduced ultrasonic vocalizations did not differ among genotypes in three cohorts of Shank 3 pups. In $+/+$ and $+/-$ pups tested at Mount Sinai on age day 8, no significant genotypes differences were detected on total number of ultrasonic calls over a 10 min test session $\left(t_{(25)}=1.587\right.$; NS), nor over the first $3 \mathrm{~min}$ of the $10 \mathrm{~min}$ session (Fig. $6 G$; $t_{(25)}=0.051$; NS). Similar results were found in pups of the WT-

found on several measures. Compared with $+/+$ controls, $+1-$ exhibited fewer bouts of anogenital sniffing $(T)$, whereas $-1-$ exhibited fewer bouts of nose-to-nose sniffing $(\boldsymbol{Q})$, push-crawl $(\boldsymbol{T})$, and more incidences of avoidance to approach (S). Both $+/-$ and $-/-$ exhibited fewerbouts ofarena exploration $(\boldsymbol{W})$ than $+/+$. Infemales, no significant differences were found among genotypes on any measures $(\boldsymbol{Q}$ X). ${ }^{*} p<0.05$ compared with $+/+$. WT-HET cohort: male: $+/+$, $N=10 ;+/-, N=14 ;$ female: $+/+, N=12 ;+/-, N=16$. Cohort 1: male: $+/+, N=15 ;+/-, N=15 ;-I-, N=$ 14; female: $+/+, N=13 ;+/-, N=14 ;-/-, N=8$. Cohort 2: male: $+/+, N=12 ;+I-, N=12 ;-I-, N=$ 14; female: $+/+, N=9 ;+I-, N=14 ;-I-, N=10$. Error bars indicate SEM. 

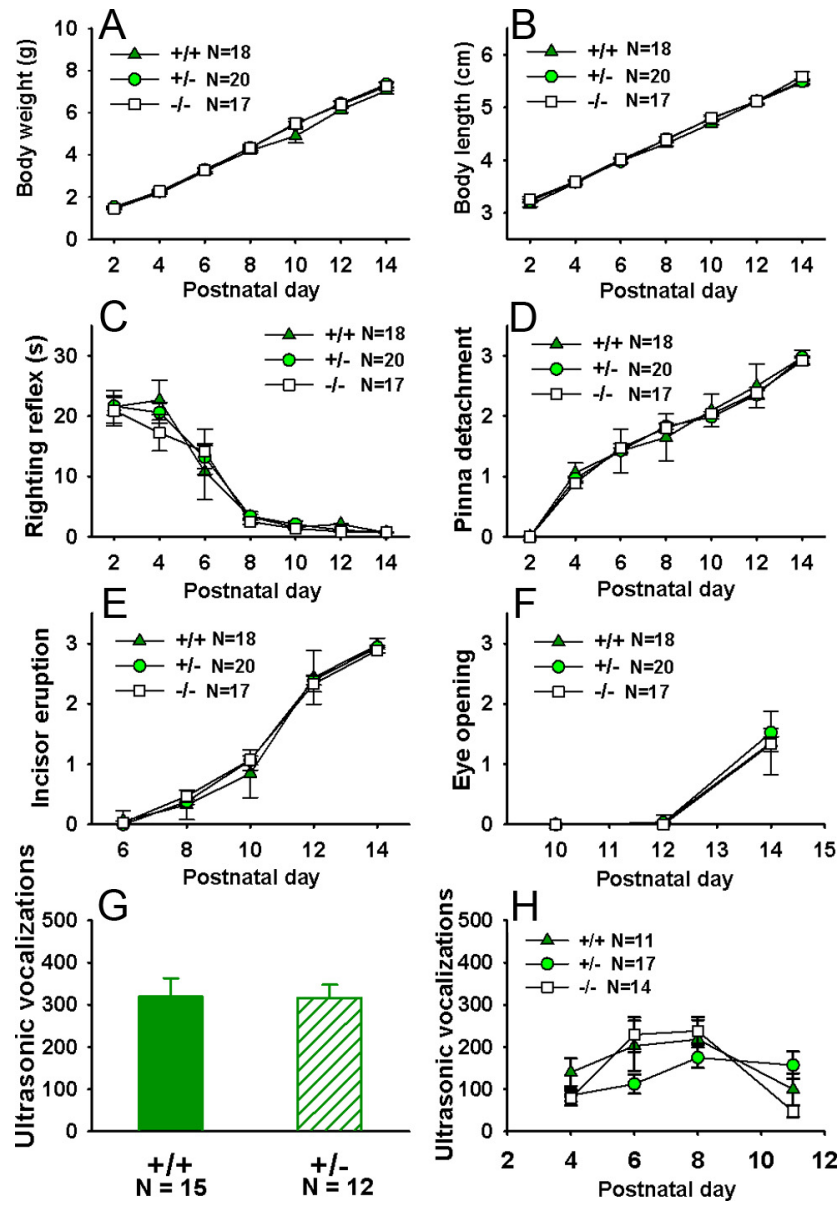

Figure 6. Normal early developmental milestones and separation-induced pup ultrasonic vocalizations in Shank $3+/+,+/-$, and $-/-$. Analysis of markers of developmental milestones revealed no genotype differences in Shank $3+/+,+/-$, and $-/-$ pups between postnatal days 2 and 14 on measures of body weight $(\boldsymbol{A})$, body length $(\boldsymbol{B})$, righting reflex $(\boldsymbol{C})$, eye opening $(\boldsymbol{D})$, pinna detachment $(\boldsymbol{E})$, incisor eruption $(\boldsymbol{F})$. Number of ultrasonic vocalizations emitted by pups separated from the nest did not differ significantly among genotypes, neither in the cohort tested on P8, at Mount Sinai (G), nor in the cohort tested between P4 and P11, at NIMH $(\boldsymbol{H})$. No sex differences were found in any genotypes, therefore sexes were collapsed for the present analysis. Error bars indicate SEM.

HET cohort tested at NIMH, on postnatal days $4,6,8$, and 11 , for 3 min on each day (data not shown). Repeated-measures ANOVAs revealed no significant genotype differences in total number of ultrasonic calls $\left(F_{(1,25)}=1.81 ; \mathrm{NS}\right)$, average call duration $\left(F_{(1,25)}=\right.$ 0.54 ; NS), or average peak call frequency $\left(F_{(1,25)}=1.14 ; \mathrm{NS}\right)$. A significant genotype difference was found in average peak call amplitude $\left(F_{(1,25)}=5.87 ; p<0.05\right)$, with calls of $+/-$ pups being at higher amplitudes compared with those of $+/+$ littermate controls in the WT-HET cohort $(p<0.05)$. Ultrasonic vocalizations during juvenile interactions did not differ between genotypes in the WT-HET cohort (data not shown). Similarly, no significant genotype differences were found on total number of calls in Cohort 1 (Fig. $6 H ; F_{(2,39)}=0.69 ;$ NS). No genotype differences were found on average call duration $\left(F_{(2,39)}=0.24\right.$; NS $)$ and peak call amplitude $\left(F_{(2,39)}=1.33\right.$; NS) (data not shown). A significant main effect of genotype was detected for average peak call frequency $\left(F_{(2,39)}=4.65 ; p<0.05\right)$ (data not shown). Post hoc analysis with the Newman-Keuls test indicated that peak call frequency was lower in $+/-$ pups compared with $-/-$ pups $(p<0.05)$. Neither $+/-$ nor $-/-$ pups differed

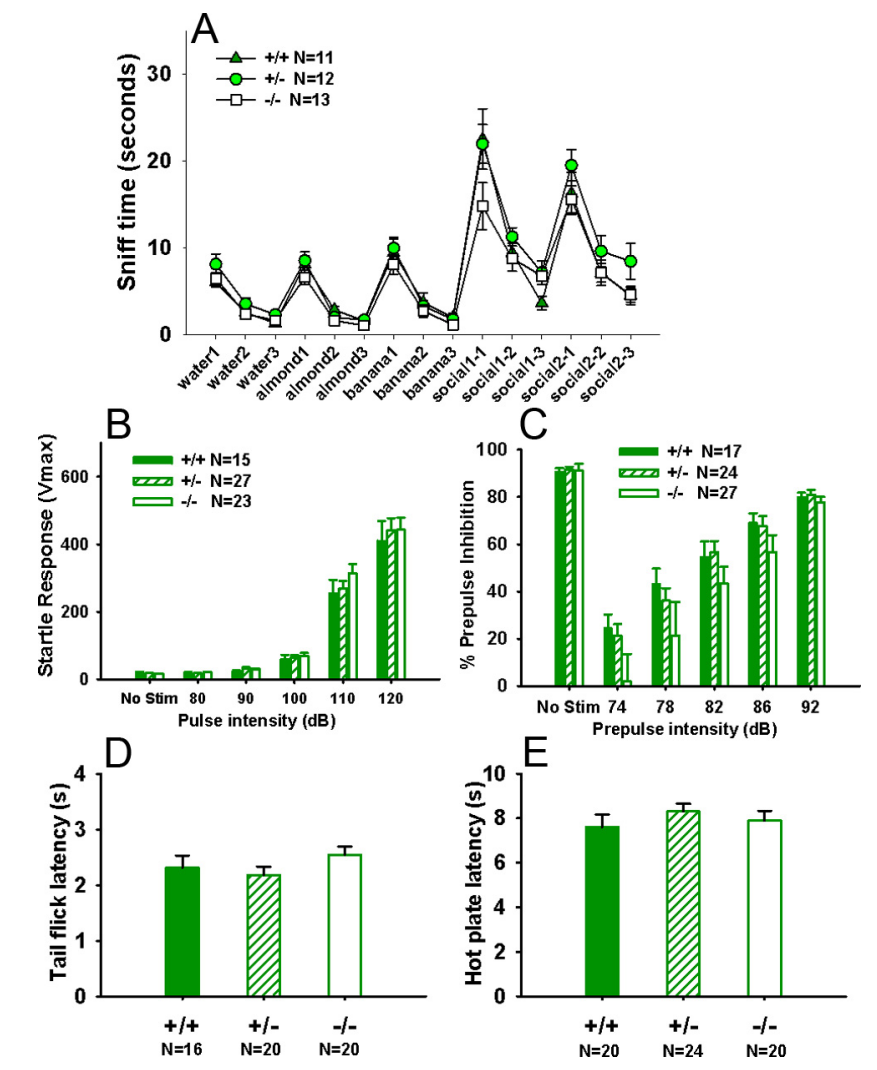

Figure 7. Normal olfaction, sensory gating, startle reflex, and nociception in Shank3 mice. A, All three genotypes showed normal olfactory habituation and dishabituation responses to sequential presentations of water, two nonsocial odors, and two social odors. Habituation was significant for all genotypes on three consecutive trials of water presentations. Dishabituation was significant for all genotypes on water to almond. No significant genotype differences in sniff time were detected across trials. $\boldsymbol{B}$, No genotype differences were found in amplitude of startle response to acoustic stimuli. $C$, No genotype differences were found in prepulse inhibition of acoustic startle. $\boldsymbol{D}, \boldsymbol{E}$, No genotype differences were found on latency to respond in the hot-plate test or tail flick test. No sex differences were detected in tests of sensory functions; therefore, sexes were collapsed for the present analysis. Error bars indicate SEM.

significantly from $+/+$ pups on this measure (data not shown).

\section{Sensory functions}

Figure 7 shows normal olfaction, sensory gating, startle response, and pain sensitivity in Shank 3 mice. Figure 7A shows intact olfactory abilities in Shank3 mice of all three genotypes on the olfactory habituation/dishabituation task. Habituation, indicated by decreased time spent in sniffing the sequence of three same odors, and dishabituation, indicated by increased time sniffing the different odor, was normal for social and nonsocial odor cues in all three genotypes: habituation to water, main effect: $+/+, F_{(2,10)}=$ 68.743, $p<0.001$; +/-, $F_{(2,11)}=22.300, p<0.001$; $-1-$, $F_{(2,12)}=41.843, p<0.001$; dishabituation water to almond: $+/+, F_{(1,10)}=91.827, p<0.001 ;+/-, F_{(1,11)}=26.547, p<$ 0.001 ; $-I-, F_{(1,12)}=56.314, p<0.001$; habituation to almond, $+/+, F_{(2,10)}=19.97, p<0.001 ;+/-, F_{(2,11)}=115.215, p<$ $0.001 ;-I-, F_{(2,12)}=42.54, p<0.001$; dishabituation almond to banana: $+/+, F_{(1,10)}=22.518, p<0.001 ;+/-, F_{(1,11)}=96.201$, $p<0.001 ;-/-, F_{(1,12)}=44.692, p<0.001$; habituation to banana, $+/+, F_{(2,10)}=23.047, p<0.001 ;+/-, F_{(2,11)}=54.941$, $p<0.001 ;-1-, F_{(2,12)}=41.524, p<0.001$; dishabituation banana to social odor 1 : $+/+, F_{(1,10)}=39.336, p<0.001 ;+/-$, 
REPETITIVE SELF-GROOMING

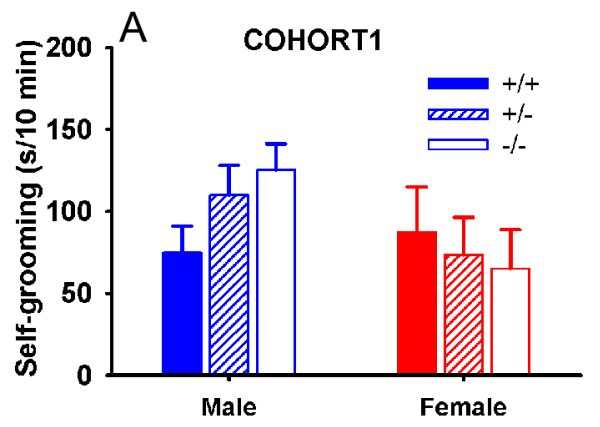

ELEVATED PLUS-MAZE
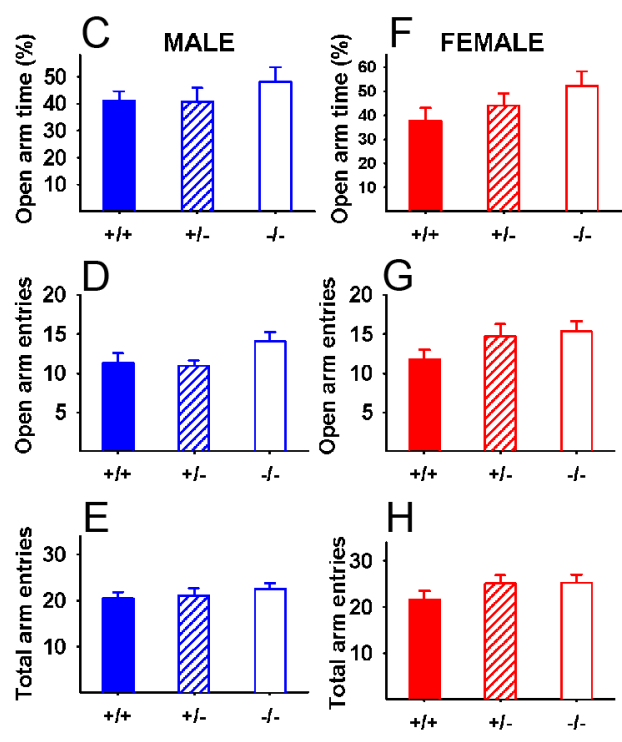

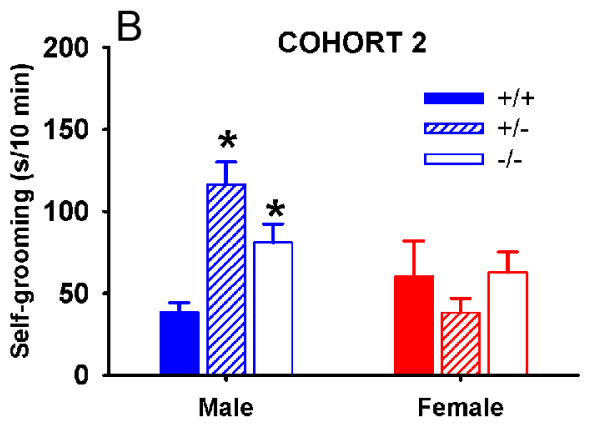

\section{LIGHT $\leftrightarrow$ DARK EXPLORATION}
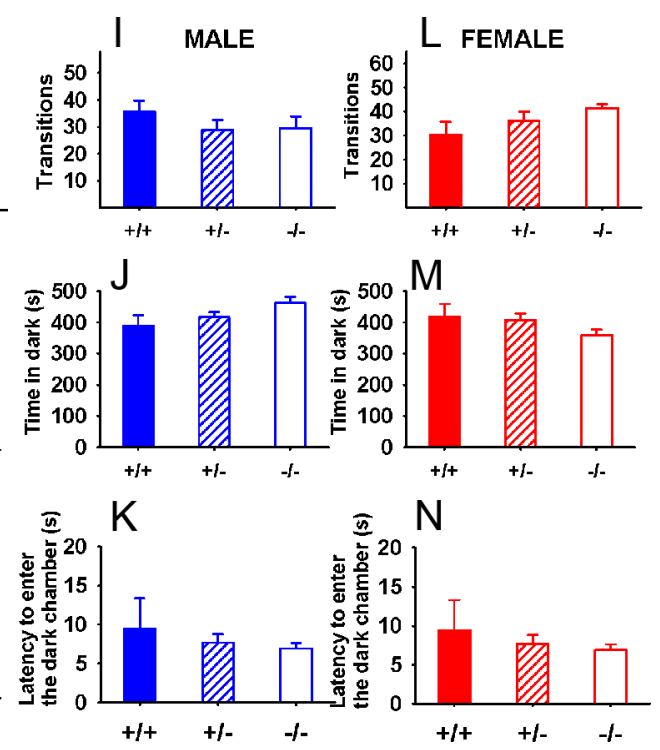

Figure 8. Increased repetitive self-grooming and normal anxiety-like behaviors in Shank3 mice. $A$, In Cohort 1, a nonsignificant trend was found for male $+/-$ and $-/-$ to exhibit higher levels of repetitive self-grooming, compared with $+/+$ controls. No significant differences of trends were found females. Male: $+/+, N=11 ;+/-, N=15 ;-/-, N=11 ;$ female: $+/+, N=9$; $+/-, N=13 ;-I-, N=9 . B$, In Cohort 2, male $+/-$ and $-/-$ exhibited significantly higher levels of repetitive self-grooming than $+/+$. No significant differences were found females. Male: $+I+, N=15 ;+I-, N=12 ;-I-, N=15 ;$ female: $+I+, N=8 ;+I-, N=14 ;-I-, N=14 .{ }^{*} p<0.05$ versus $+/+$. $C-H$, No genotype differences were detected in the elevated plus-maze test, on measures of percentage open arm time $(\boldsymbol{C}, \boldsymbol{F})$, number of open arm entries $(\boldsymbol{D}, \boldsymbol{G})$, and total number of entries into open + closed arms $(\boldsymbol{E}, \boldsymbol{H})$. Males: $+/+, N=11 ;+/-, N=$ $13 ;-I-, N=13 ;$ females: $+I+, N=9 ;+I-, N=11 ;-I-, N=14$. I-N, No genotype differences were detected in the light $\leftrightarrows$ dark exploration test, on measures of number of transitions between compartments $(\boldsymbol{I}, \boldsymbol{L})$, time spent in the dark chamber $(\boldsymbol{J}, \boldsymbol{M})$, and latency to enter the dark chamber $(\boldsymbol{K}, \boldsymbol{N})$. Males: $+/+, N=11 ;+/-, N=13 ;-/-, N=13 ;$ females: $+/+, N=9$; $+I-, N=11 ;-I-, N=14$. Error bars indicate SEM.

$F_{(1,11)}=82.609, p<0.001 ;-/-, F_{(1,12)}=25.816, p<0.001$; habituation to social odor $1:+/+, F_{(2,10)}=27.468, p<0.001$; $+/-, F_{(2,11)}=34.912, p<0.001 ;-/-, F_{(2,12)}=4.754, p<0.05$; dishabituation social odor 1 to social odor 2 : $+/+, F_{(1,10)}=$ 32.797, $p<0.001$; $+1-, F_{(1,11)}=26.230, p<0.001 ;-I-$, $F_{(1,12)}=20.636, p<0.001$; habituation to social odor $2,+/+$, $F_{(2,10)}=29.474, p<0.001 ;+/-, F_{(2,11)}=14.307, p<0.001$; $-I-, F_{(2,12)}=26.636, p<0.001$. No significant genotype differences were detected across trials. No sex differences were detected and sexes were collapsed for statistical analysis. Figure $7 B$ shows normal acoustic startle responses at five different decibel levels across genotypes $\left(F_{(2,62)}=0.45\right.$; NS). Figure $7 C$ show normal sensorimotor gating in prepulse inhibition of acoustic startle at all prepulse levels across genotypes $\left(F_{(2,65)}=0.05 ; \mathrm{NS}\right)$. Figure 7 , $D$ and $E$, shows pain sensitivity in Shank3 mice. No significant genotype differences were detected on hot plate $\left(F_{(2,63)}=0.70\right.$; NS) and tail flick $\left(F_{(2,61)}=1.18\right.$; NS). No sex differences were found in the hot-plate test and the tail flick test.
Repetitive self-grooming

Figure $8 A$ shows repetitive self-grooming in Cohort 1 . A trend was seen in males for $+/-$ and $-/-$ to show higher levels of self-grooming than $+/+$ in a 10 min test conducted in an empty cage $\left(F_{(2,34)}=2.02 ; p=0.15 ; \mathrm{NS}\right)$. In females, self-grooming was similar across genotypes $\left(F_{(2,28)}=0.18\right.$; NS). In Cohort 2 (Fig. $8 B)$, male Shank3 mutants displayed high self-grooming $\left(F_{(2,39)}=13.56 ; p<0.001\right)$, with $+/-(p<0.05)$ and $-/-(p<$ $0.01)$ exhibiting significantly higher levels of self-grooming than $+/+$. No significant genotype differences were found in females $\left(F_{(2,33)}=1.25\right.$; NS $)$.

\section{Anxiety-related behaviors}

No genotype differences were detected on measures of anxietyrelated behaviors in Shank3 mice. On the elevated plus-maze (Fig. $8 C-H$ ), no significant genotype differences were found in either males or females on percentage time spent in the open arms (males: $F_{(2,34)}=0.73$, NS; female: $\left.F_{(2,31)}=2.06, \mathrm{NS}\right)$, open arm 
entries (males: $F_{(2,34)}=2.12$, NS; female: $F_{(2,31)}=2.99$, NS), or total arm entries (males: $F_{(2,34)}=0.33$, NS; female: $F_{(2,31)}=$ $1.97, \mathrm{NS})$. In the light $\leftrightarrows$ dark exploration test (Fig. $8 I-N$ ), no significant genotype differences were found in either males or females on number of transitions (males: $F_{(2,22)}=0.91$, NS; female: $F_{(2,29)}=1.62$, NS), time spent in the dark compartment (males: $F_{(2,22)}=0.58$, NS; female: $F_{(2,29)}=$ 0.88 , NS), or latency to enter the dark compartment (males: $F_{(2,22)}=1.41$, NS; female: $F_{(2,29)}=1.54$, NS).

\section{Morris water maze}

Figure 9 shows performance of Cohort 2 males in the Morris water maze spatial learning task. During the acquisition training, all three genotypes showed similar learning curves over $5 \mathrm{~d}$. The main effect of day was significant for latency to reach the platform within each of the three genotypes (Fig. $9 A ;+/+, F_{(4,28)}=$ 12.69, $p<0.001$; $+/-, F_{(4,36)}=30.95$, $p<0.001 ;-/-, F_{(4,28)}=12.18, p<$ $0.001)$. Latency to reach the hidden platform was not significant across genotypes $\left(F_{(2,23)}=1.70\right.$; NS). Swim speed was similar across genotypes, with no differences in the main effect of day (data not shown) $\left(+/+, F_{(4,28)}=1.30, \mathrm{NS} ;+/-, F_{(4,36)}=\right.$ $1.22, \mathrm{NS} ;-/-, F_{(4,28)}=2.13$, NS) and in the genotype effect $\left(F_{(2,23)}=0.49 ; \mathrm{NS}\right)$. In the probe trial conducted $3 \mathrm{~h}$ after the final training trial, all genotypes spent significantly more time in the training quadrant compared with the other three quadrants (Fig. 9C; $+/+, F_{(3,21)}=12.87$, $p<0.001 ;+/-, F_{(3,30)}=11.70, p<$ $\left.0.001 ;-/-, F_{(3,18)}=6.17, p<0.01\right)$. Selective quadrant search was also measured by platform crossings. $+/-$ and $-/-$ made significantly more crossings over the previous platform location than equivalent locations in at least two other quadrants. $+/+$ showed a trend for selective quadrant search (data not shown) $\left(+/+, F_{(3,21)}=2.01, p=0.14 ;+/-\right.$, $F_{(3,30)}=9.72, p<0.001 ; F_{(3,18)}=5.10$, $p<0.05)$. During reversal training, which started $35 \mathrm{~d}$ after the completion of acquisition trials, all three genotypes acquired the task within $4 \mathrm{~d}$. In all three genotypes, the main effect of day was significant for latency to reach the new hidden platform (Fig. 9B; $F_{(3,21)}=9.75, p<0.001 ;+/-, F_{(3,24)}=13.85, p<0.001 ;-/-$, $\left.F_{(3,18)}=4.10, p<0.05\right)$. The genotype effect for latency to reach the hidden platform was not significant $\left(F_{(2,21)}=0.49\right.$; NS). The main effect of day was not significant for swim speed in all three genotypes (data not shown) $\left(+/+, F_{(3,21)}=0.37, \mathrm{NS} ;+/-, F_{(3,24)}\right.$ $\left.=1.07, \mathrm{NS} ;-/-, F_{(3,18)}=1.32, \mathrm{NS}\right)$. In the probe trial conducted $3 \mathrm{~h}$ after the last reversal training trial, $+/+$ and $+/-$ showed significant selective quadrant search, spending more time in the new training quadrant than time in at least two other quadrants, whereas the $-/-$ group did not (Fig. $9 D ;+/+, F_{(3,21)}=10.64$,
ACQUISITION

REVERSAL
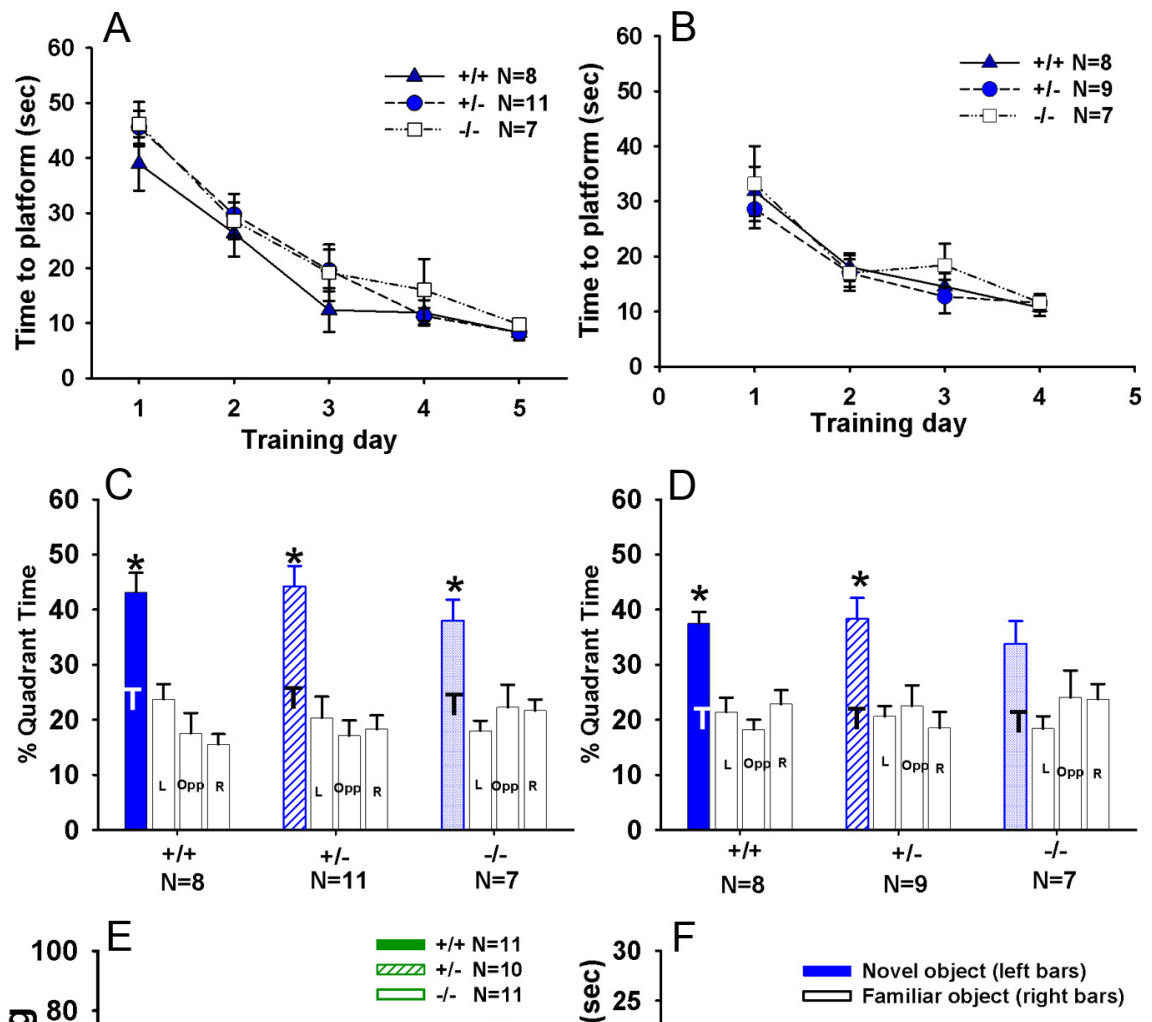

Figure 9. Learning and memory in Shank3 mice. Spatial learning in the Morris water maze test was normal in all three genotypes of male Shank3 mice. No genotype differences were found in either acquisition or reversal training. $\boldsymbol{C}$, In the probe trial following acquisition training trials, all three genotypes exhibited selective quadrant search, spending more time in the trained quadrant than in two or more other quadrants. $\boldsymbol{D}$, In the probe trial following reversal training trials, $+/+$ and $+/-$ spent time in the trained quadrant. $\boldsymbol{E}$, Normal contextual and cued fear conditioning in Shank3 mice. No genotype differences were detected in freezing scores in the posttraining session on day 1. Contextual conditioning (day 2) and cued conditioning (day 3 ) did

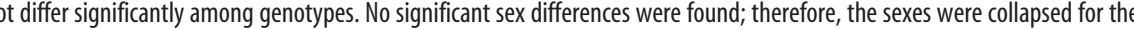
present analysis. $\boldsymbol{F}$, Impaired novel object recognition in Shank3 - / - + / + and + / - spent more time sniffing the novel object than the familiar object, whereas $-1-$ exhibited low sniffing behavior toward both objects. Error bars indicate SEM. ${ }^{*} p<0.05$ trained quadrant compared to at least two other quadrants.

$\left.p<0.01 ;+/-, F_{(3,24)}=6.06, p<0.01 ;-/-, F_{(3,18)}=2.29, \mathrm{NS}\right)$. Similarly, $+/+$ and $+/-$ made more crossings over the new platform location than equivalent locations in at least two other quadrants, whereas the $-/-$ did not (data not shown) $(+/+$, $F_{(3,21)}=3.07, p<0.05 ;+/-, F_{(3,24)}=4.86, p<0.01 ;-/-, F_{(3,18)}$ $=0.58$, NS). Similar results were found in Cohort 1 male mice (data not shown). All three genotypes displayed similar learning curves across the $5 \mathrm{~d}$ of acquisition. The main effect of day was significant for latency to reach the platform within each of the three genotypes $\left(+/+, F_{(4,48)}=24.50, p<0.001 ;+/-, F_{(4,52)}=\right.$ $\left.25.23, p<0.001 ;-/-, F_{(4,52)}=34.23, p<0.001\right)$. A significant genotype effect was found for latency to reach the hidden platform $\left(F_{(2,38)}=5.197 ; p<0.01\right)$. Scheffé's post hoc tests indicated a significant difference between $+/-$ and $-/-(p<0.01)$, but 
neither +/ - nor - / - was significantly different from +/ + controls. Similarly, the main effect of day was significant for swim speed in all three genotypes $\left(+/+, F_{(4,48)}=3.31, p<0.05\right.$; $+/-$, $\left.F_{(4,52)}=2.89, p<0.05 ;-/-, F_{(4,52)}=4.87, p<0.01\right)$, and the genotype factor was significant for swim speed $\left(F_{(2,38)}=3.62 ; p<\right.$ $0.05)$. Scheffé's post hoc tests revealed that $-/-$ swam at a significantly slower speed than $+/+$ controls $(p<0.01)$, along with a trend for slower swim speed in $+/-$ compared with $+/+(p=$ 0.057 ; NS). In the probe trial conducted $3 \mathrm{~h}$ after the final training trial, all genotypes displayed selective quadrant search, spending significantly more time in the training quadrant compared with the other three quadrants $\left(+/+, F_{(3,36)}=13.37, p<0.001 ;+/-\right.$, $\left.F_{(3,39)}=20.84, p<0.001 ;-/-, F_{(3,39)}=4.56, p<0.05\right) .+1+$ and $+/-$ made significantly more crossings over the previous platform location than equivalent locations in the other three quadrants. $-/-$ showed a nonsignificant trend for more crossings over the previous platform location $\left(+/+, F_{(3,36)}=13.08\right.$, $p<0.001 ;+1-, F_{(3,39)}=27.63, p<0.001 ; F_{(3,39)}=2.60, p=$ 0.066). During reversal training, which started $3 \mathrm{~d}$ after the completion of acquisition trials, all three genotypes acquired the task within $4 \mathrm{~d}$. In all three genotypes, the main effect of day was significant for latency to reach the new hidden platform $(+/+$, $F_{(3,21)}=21.22, p<0.001 ;+/-, F_{(3,24)}=9.57, p<0.001 ;-/-$, $\left.F_{(3,24)}=11.31, p<0.001\right)$ and for swim speed $\left(+/+, F_{(3,21)}=\right.$ $6.56, p<0.01 ;+/-, F_{(3,24)}=5.11, p<0.01 ;-/-, F_{(3,24)}=2.95$, $p<0.05)$. In the probe trial conducted $3 \mathrm{~h}$ after the last reversal training trial, all three genotypes showed significant selective quadrant search, spending more time in the new training quadrant than the other three quadrants $\left(+/+, F_{(3,21)}=5.87, p<\right.$ $\left.0.01 ;+/-, F_{(3,24)}=6.39, p<0.01 ;-/-, F_{(3,24)}=9.76, p<0.01\right)$ and making more crossings over the new platform location than equivalent locations in the other quadrants $\left(+/+, F_{(3,21)}=19.67\right.$, $p<0.01 ;+/-, F_{(3,24)}=3.97, p<0.05 ;-/-, F_{(3,24)}=7.79, p<$ $0.001)$. Thus, it appears that Shank3 mutant mice acquired the hidden platform location using distal spatial cues, while showing deficits in the reversal probe trial, an impairment that was inconsistent across cohorts.

\section{Contextual and cued conditioning}

As shown in Figure 9, no genotype differences were found on contextual and cued fear conditioning in Cohort 2 mice. Since no sex differences were found on any measures, data were analyzed with sexes combined. In the training session, freezing behavior before presentations of cue-shock pairings was minimal and did not differ across genotypes $\left(F_{(2,29)}=0.64\right.$; NS) (data not shown). No significant genotype differences in postshock freezing were found on the training day $\left(F_{(2,29)}=1.97 ; \mathrm{NS}\right)$. In the contextual conditioning test, no significant genotype differences were found on freezing $\left(F_{(2,29)}=1.54 ; \mathrm{NS}\right)$. In the cued conditioning test, no significant genotype differences were found in freezing behavior, either before cue presentation $\left(F_{(2,29)}=0.49\right.$; NS) or after cue presentation $\left(F_{(2,29)}=0.25 ; \mathrm{NS}\right)$. Cohort 1 similarly displayed no genotype differences in fear conditioning. In the training session, minimal levels of freezing behavior were seen before the presentations of cue-shock pairings (data not shown). A significant genotype effect was found during the training session in postshock freezing $\left(F_{(2,79)}=6.65 ; p<0.01\right)$, with $+/-$ and $-/-$ displaying higher levels of freezing compared with $+/+$ controls ( $p<0.05$ for each comparison). In the contextual conditioning test session, no significant genotype differences were found on freezing $\left(F_{(2,79)}=2.29\right.$; NS). In the cued conditioning test session, no significant genotype differences were found in freezing behavior, either before cue presentation $\left(F_{(2,79)}=1.07\right.$; NS) or after cue pre- sentation $\left(F_{(2,79)}=1.42\right.$; NS). Therefore, on this test of emotional memory, Shank3 mutants displayed normal performance.

\section{Novel object recognition}

Cohort 2 null mutants displayed an apparent deficit in novel object recognition, as shown in Figure 9F. Preference for the novel object over the familiar object was found in male $+/+$ $\left(F_{(1,9)}=21.24 ; p<0.01\right)$ and $+/-\left(F_{(1,10)}=7.55 ; p<0.05\right)$, but not in male $-/-\left(F_{(1,17)}=3.91\right.$; NS $)$. Similar results were found in females (data not shown). Preference for the novel object over the familiar object was found in female $+/+\left(F_{(1,7)}=36.85 ; p<\right.$ $0.001)$ and $+/-\left(F_{(1,14)}=6.33 ; p<0.05\right)$, but not in female $-/-$ $\left(F_{(1,13)}=0.16\right.$; NS). Males showed a significant genotype effect on total sniff time $\left(F_{(2,44)}=7.18 ; p<0.01\right)$, with $-/-$ lower than $+/+(p<0.001)$ and $+/-(p<0.001)$. Females showed a nonsignificant trend $\left(F_{(2,40)}=2.85 ; p=0.08\right)$ for less total sniff time in $-/-$. Consistent results were found in Cohort 3 (data not shown). Preference for the novel object over the familiar object was found in $+/+\left(F_{(1,9)}=17.93 ; p<0.01\right)$ and $+/-\left(F_{(1,9)}=\right.$ $25.00 ; p<0.01)$, but not in $-/-\left(F_{(1,8)}=2.12\right.$; NS $)$. As in Cohort $2,-/-$ of Cohort 3 exhibited lower total sniff time compared with $+/+$ controls $\left(F_{(2,26)}=8.31 ; p<0.01\right)$, with $-/$ - lower than $+/+(p<0.01)$ and $+/-(p<0.05)$. Lower overall exploration complicates the interpretation of apparent cognitive deficits in novel object recognition.

\section{Rotarod motor learning}

Shank3 mice of all three genotypes had a tendency to ride the rotarod beam around rather than walking forward. This unusual strategy occurs occasionally in all mice, but was considerably more frequent in this line of Shank3. Therefore, as shown in Figure 10, rotarod scores in Cohorts 1, 2, and 3 were scored for latency to either fall or ride the rod around. Using this either/or criterion, we detected a significant genotype effect across the six rotarod training trials in Cohort 1 males $\left(F_{(2,43)}=7.00 ; p<0.01\right)$. Post hoc comparisons indicated that $-/-$ had shorter latencies to fall off or ride the rod around compared with $+/+$ controls $(p<$ $0.05)$, significant on trial $1(p<0.05)$, trial $3(p<0.01)$, and trial $4(p<0.01)$. In contrast, $+/-$ fell/rode sooner than $+/+$ on trial $1(p<0.05)$, but not on the subsequent trials. The genotype effect was not significant in females across six trials $\left(F_{(2,27)}=0.10\right.$; NS). Similar results were found in Cohort 2. In males, a significant genotype effect was detected across six trials $\left(F_{(2,26)}=14.82 ; p<\right.$ $0.01)$. Post hoc comparisons indicated that $-/-$ had shorter latencies to fall compared with $+/+$ controls $(p<0.01)$, significant on all trials (trial 1, $p<0.02$; trial 2, $p<0.01$; trial 3, $p<0.05$; trial 4, $p<0.05$; trial 5, $p<0.05$; and trial 6, $p<0.01)$. $+/-$ did not differ significantly from $+/+$. No significant genotype differences were found in females $\left(F_{(2,17)}=3.00\right.$; NS). In Cohort 3, a significant genotype effect was found in both males $\left(F_{(2,36)}=\right.$ $4.71 ; p<0.05)$ and females $\left(F_{(2,27)}=6.82 ; p<0.01\right)$. In males, post hoc comparisons indicated that $-1-$ had shorter latencies to fall off or ride the rod around compared with $+/+$ controls $(p<$ $0.05)$ across six trials, but did not differ from $+/+$ significantly on each individual trials. In females, post hoc comparisons indicated that $-1-$ had shorter latencies to fall off or ride the rod around compared with $+/+$ controls $(p<0.01)$, significant on trial 4 ( $p<0.05)$, trial $5(p<0.05)$, and trial $6(p<0.05)$. Cohort 3 was also scored for latency to fall, a more stringent criterion. In males, a nonsignificant trend was seen for $-/-$ to fall sooner than $+/+$ controls (Fig. $10 E ; F_{(2,36)}=1.81 ; p=0.18$ ). A similar trend was detected in females (Fig. $10 F ; F_{(2,27)}=1.92 ; p=0.16$ ). These 

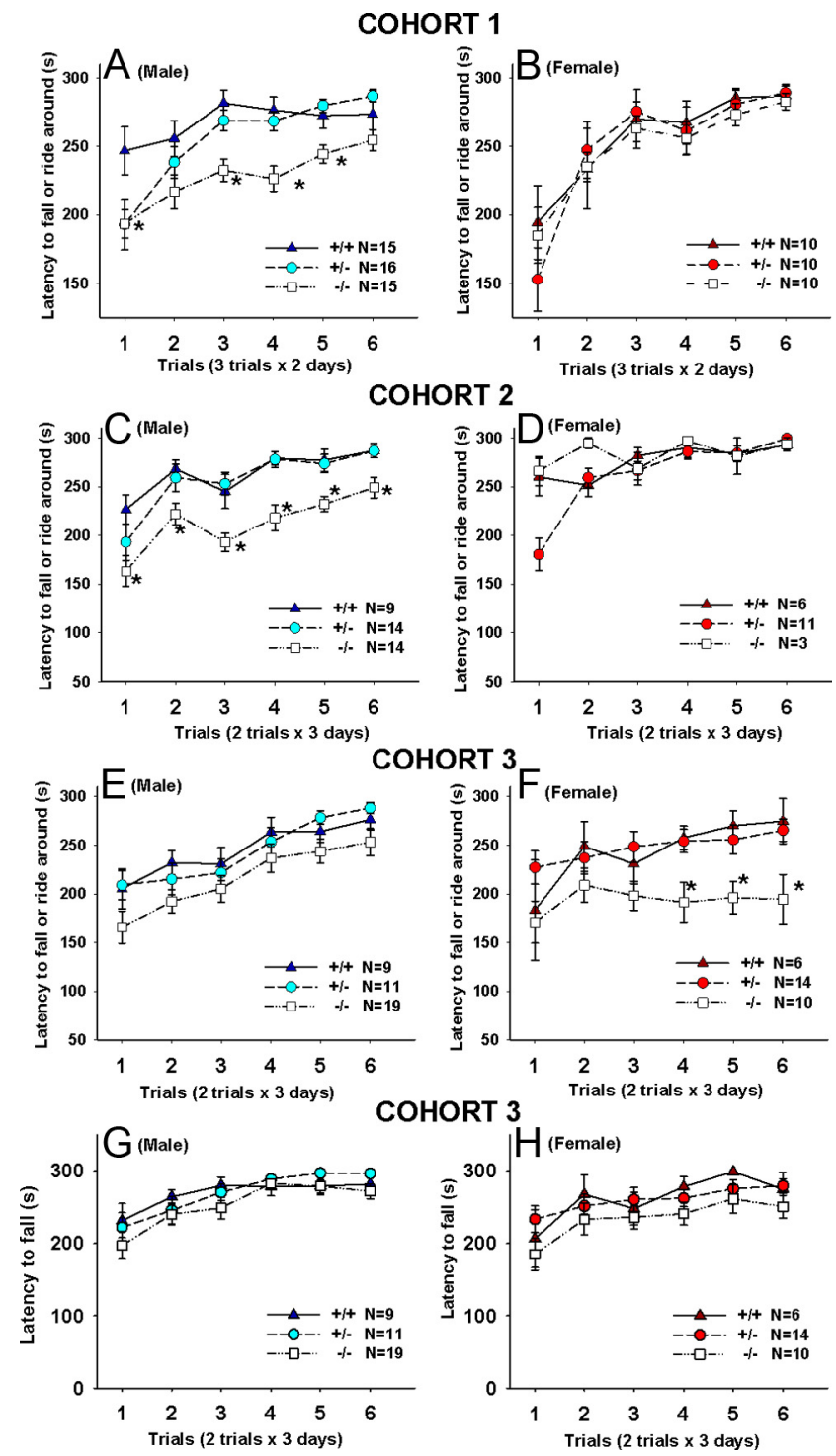

Figure 10. Rotarod motor learning deficits in male Shank3 null mutant mice. Rotarod scores in Cohorts 1, 2, and 3 were evaluated for latency to either fall or to ride the rod around. Results collected using this criterion revealed significant genotype differences in all three cohorts of males. - I- males exhibited significantly shorter latencies to fall off the rotating rod or to ride the rod around, compared with $+/+$ males $(\boldsymbol{A}, \boldsymbol{C}, \boldsymbol{E})$. In females, no significant genotypes differences were found in Cohorts 1 and $2(\boldsymbol{B}, \boldsymbol{D})$. In Cohort 3, - / - females exhibited significantly shorter latencies to fall or ride around compared with $+/+$ females $(\boldsymbol{F})$. Cohort 3 was also scored with a more stringent criterion, latency to fall only. A nonsignificant trend was found for Cohort 3 $-/-$ males to fall sooner than $+/+$ males $(\boldsymbol{G})$. A similar nonsignificant trend was found in Cohort 3 females $(\boldsymbol{H}) .{ }^{*} p<0.05$ compared with $+/+$ on each individual trial. Error bars indicate SEM.

results indicate impaired rotarod motor learning in male Shank3 mutants only, based on an unusual motoric strategy.

\section{Discussion}

Hemizygous mutations in SHANK3 are among the most frequent of the rare genetic variants associated with autism (Bourgeron, 2009; Buxbaum, 2009). The SHANK3 mutation is additionally present in all of the $\sim 500$ individuals with the chromosome 22q13 deletion that causes Phelan-McDermid syndrome, a neurodevelopmental disorder characterized by communication and cognitive disabilities along with features of autism (Phelan, 2008; Bonaglia et al., 2011; Herbert, 2011). We investigated a compre- hensive range of behavioral phenotypes relevant to the symptoms of autism and Phelan-McDermid syndrome in mice with hemizygous and homozygous mutations in Shank3 at the ankyrin repeat domain, compared with their wild-type littermates, in three independent cohorts of males and females at infant, juvenile, and adult ages, to expand our initial report in Shank3 hemizygous mice (Bozdagi et al., 2010).

Present data indicate that basal glutamatergic synaptic transmission and long-term potentiation in the hippocampus were impaired in null mutants, providing evidence that Shank3 is necessary for normal hippocampal function. These results are consistent with our previous findings in Shank3 heterozygous mice (Bozdagi et al., 2010) and with LTP deficits in Shank $3^{\text {e4-9 }}$ mutant mice reported by Wang et al. (2011). Our data also indicate impaired induction and maintenance of LTP in homozygous mice. Long-term depression was not different across genotypes.

Of the three diagnostic symptoms of autism, the most specific is qualitatively unusual reciprocal social interactions (American Psychiatric Association, 1994; Lord et al., 2000). Lower numbers of reciprocal social interactions were detected on several parameters in juvenile Shank 3 male heterozygote and null mutant mice. Cohort 1 displayed less following and trended toward more active social avoidance when paired with juvenile B6 partners in the Noldus Phenotyper arena. Juvenile females did not differ from wild-type littermate controls on reciprocal social interactions, reminiscent of the 4:1 male-female prevalence of autism. Similar, although not identical, patterns of reduced social parameters were detected in Cohort 2, and in males of the WT-HET group. One potential contributing factor to the variability in the juvenile interaction scores across cohorts could be early handling. WTHET cohort and Cohort 1 mice were split into subgroups that were tested for either pup vocalizations or for developmental milestones. Both tests involve handling the pups for $\sim 5 \mathrm{~min}$ every other day for a total of 4-7 d. Cohorts 2 and 3 were not handled by the experimenter before age $21 \mathrm{~d}$. Another factor that might be relevant to juvenile behaviors is the age of the mother. The WT-HET cohort was generated from mice imported from Mount Sinai, for which the breeders were $>6$ months of age after quarantine. Breeders used to generate Cohorts 1 and 2 were between 2.5 and 4 months of age. Differences across cohorts underscore the importance of testing at least two independent groups of mice, each with large $N$ values, to control for environmental variability across experiments, and to evaluate internal consistency across related behavioral parameters.

In contrast, adult Shank3 mice of all genotypes and both sexes in all three cohorts displayed normal sociability in our automated three-chambered social approach task. Our findings of intact social approach in adult mice with the Shank3 mutation in the ankyrin repeat domain are consistent with reports in two other lines of Shank3 mice with mutations at the ankyrin site (Peça et al., 2011; Wang et al., 2011).

The second diagnostic symptom of autism is deficits in communication (American Psychiatric Association, 1994; Lord et al., 2000). In the present study, all three genotypes of Shank3 mice displayed normal levels of interest in social pheromones. During male responses to female urinary pheromones, reductions in ultrasonic vocalizations were detected in some but not all cases, and scent marking by the male subjects was normal across genotypes, indicating relatively normal responses to female olfactory cues. During male-female reciprocal social interactions, similar levels of ultrasonic vocalizations were emitted across genotypes. Trends were seen for fewer male-female interactions in Cohort 1 , and for fewer vocalizations in Cohorts 1 and 2, in the null mutants and 
heterozygotes, in agreement with our previous report (Bozdagi et al., 2010); however, these did not reach statistical significance in the present study. Across genotypes and cohorts, pups emitted normal levels of ultrasonic vocalizations when removed from the dam and nest.

The third diagnostic symptom of autism includes motor stereotypes, repetitive behaviors, insistence on sameness, and restricted interests (Lord et al., 2001; Bishop et al., 2007; Kim and Lord, 2010). Significantly higher levels of repetitive selfgrooming were detected in the male null mutants and heterozygote mice of Cohort 2, with a trend for higher self-grooming in Cohort 1. Female mutants did not display higher self-grooming, again indicating stronger abnormalities in males than females, consistent with the male/female differential in autism. Probe trial deficits specifically in the reversal phase of the Morris water maze task, detected in Cohort 2 only, indicate a minor insistence on sameness, a component of the third diagnostic symptom of autism.

Associated symptoms that appear in high percentages of individuals with autism and Phelan-McDermid syndrome include cognitive disabilities, anxiety, hypersensitivity and hyposensitivity to sensory stimuli, sleep disruption, seizures, aggression, and motor impairments (Edelson et al., 1999; Tsai, 1999; Rinehart et al., 2001; Pellock, 2004; West et al., 2009; Humphrey and Symes, 2011; Lloyd et al., 2011). Our Shank3 mutant mice showed no differences on two standard anxiety-related tasks, elevated plusmaze and light $\leftrightarrows$ dark transitions. Responses to acoustic and tactile sensory stimuli did not differ across genotypes in tests of acoustic startle, prepulse inhibition of acoustic startle, hot plate, and tail flick, with one exception, reduced nociception in female nulls on the tail flick test. Olfactory abilities were normal for social and nonsocial odors. No episodes of seizures, no aberrant nesting or sleeping patterns in the home cage, and no unusual levels of aggression were noted in any cohort of Shank3 mice. Motor abilities were normal in null mutants on open-field locomotion, gait pattern, and grip strength. Developmental milestones and general health measures, including body weight and spontaneous stereotypies, did not differ across genotypes at any age. In contrast to the hypotonia, which characterizes infants with Phelan-McDermid syndrome (Phelan, 2008; Strenge et al., 2008), righting reflex, grip strength, and body and limb tone were normal across development.

Cognitive abilities were generally intact on the Morris water maze hidden platform learning and contextual and cued fear conditioned learning and memory for all genotypes and both sexes. Lack of selective search on the probe trial in water maze reversal was seen in Shank3 null mutants, but not consistently across cohorts. In contrast, performance on novel object recognition was impaired in Shank3 null mutants. Novel object recognition is a form of declarative memory, dependent on intact CA1 hippocampal function (Rampon and Tsien, 2000; Hammond et al., 2004). LTP impairment in the hippocampus of Shank3 null mutants could contribute to their deficits in recognition memory.

Motor learning difficulties have been reported in Phelan-McDermid syndrome, and in some children and adults with autism (Ghaziuddin and Butler, 1998; Rinehart et al., 2001; Moruzzi et al., 2011). Rotarod performance was impaired in Shank3 null mutants in both cohorts, primarily in males, again suggestive of the male/female differential in autism. Specifically, many Shank3 mice used the strategy of riding the rod around rather than walking forward, independent of genotype. Acquisition deficits were detected when training was administered either as two daily trials for $3 \mathrm{~d}$, or as three daily trials for $2 \mathrm{~d}$, confirming the robustness of findings. While hanging onto the rotating rod is commonly seen in one or two individuals within a group of normal mice, the high frequency of this unusual strategy in Shank 3 mutant mice will be important to investigate further, for relevance to motor abnormalities in Phelan-McDermid syndrome.

Consistency of findings across independent cohorts is essential for drawing conclusions about the strength of an endophenotype. Rigorous analysis of behavioral results from our three cohorts of Shank3 mutants, in multiple corroborating tasks relevant to the diagnostic and associated symptoms of autism, supports the interpretation that targeted mutation of the ankyrin domain of the Shank3 gene produces generally mild phenotypes in mice. Our findings are consistent with behaviors briefly reported in two other lines of mice with Shank3 mutations in the ankyrin repeat domain, including predominantly normal social interaction (Peça et al., 2011; Wang et al., 2011), fewer vocalizations and impaired rotarod motor learning (Wang et al., 2011), and moderate levels of repetitive behaviors (Peça et al., 2011; Wang et al., 2011). Similarly, our findings are consistent with the normal cognitive abilities in Shank3 heterozygotes with the mutation targeting the Homer binding site, which displayed social abnormalities only on aggression (Bangash et al., 2011), an associated symptom of autism. In contrast, Shank3 null mutants with targeted mutations in the PDZ domain displayed severe selfgrooming and skin lesions, impaired locomotion, and major reductions in social behaviors (Peça et al., 2011). Different sets of proteins bind to the ankyrin, PDZ, and Homer regions of the Shank protein (Tu et al., 1999; Sheng and Kim, 2000). Dichotomies in phenotypic outcome based on mutations at distinct sites within the SHANK3 gene sequence may reveal divergent downstream signaling mechanisms responsible for the variability and severity of symptoms across individuals with autism and PhelanMcDermid syndrome.

\section{References}

Abu-Elneel K, Liu T, Gazzaniga FS, Nishimura Y, Wall DP, Geschwind DH, Lao K, Kosik KS (2008) Heterogeneous dysregulation of microRNAs across the autism spectrum. Neurogenetics 9:153-161.

American Psychiatric Association (1994) Diagnostic and statistical manual of mental disorders, Ed 4. Washington, DC: American Psychiatric Association.

Bailey KR, Pavlova MN, Rohde AD, Hohmann JG, Crawley JN (2007) Galanin receptor subtype 2 (GalR2) null mutant mice display an anxiogeniclike phenotype specific to the elevated plus-maze. Pharmacol Biochem Behav 86:8-20.

Bainbridge NK, Koselke LR, Jeon J, Bailey KR, Wess J, Crawley JN, Wrenn CC (2008) Learning and memory impairments in a congenic C57BL/6 strain of mice that lacks the $\mathrm{M}_{2}$ muscarinic acetylcholine receptor subtype. Behav Brain Res 190:50-58.

Bangash MA, Park JM, Melnikova T, Wang D, Jeon SK, Lee D, Syeda S, Kim J, Kouser M, Schwartz J, Cui Y, Zhao X, Speed HE, Kee SE, Tu JC, Hu JH, Petralia RS, Linden DJ, Powell CM, Savonenko A, et al. (2011) Enhanced polyubiquitination of Shank3 and NMDA receptor in a mouse model of autism. Cell 145:758-772.

Baron MK, Boeckers TM, Vaida B, Faham S, Gingery M, Sawaya MR, Salyer D, Gundelfinger ED, Bowie JU (2006) An architectural framework that may lie at the core of the postsynaptic density. Science 311:531-535.

Bertaso F, Roussignol G, Worley P, Bockaert J, Fagni L, Ango F (2010) Homerla-dependent crosstalk between NMDA and metabotropic glutamate receptors in mouse neurons. PLoS One 5:e9755.

Bevins RA, Besheer J (2006) Object recognition in rats and mice: a one-trial non-matching-to-sample learning task to study "recognition memory." Nat Protoc 1:1306-1311.

Bishop SL, Richler J, Cain AC, Lord C (2007) Predictors of perceived negative impact in mothers of children with autism spectrum disorder. Am J Ment Retard 112:450-461. 
Böckers TM, Mameza MG, Kreutz MR, Bockmann J, Weise C, Buck F, Richter D, Gundelfinger ED, Kreienkamp HJ (2001) Synaptic scaffolding proteins in rat brain. Ankyrin repeats of the multidomain Shank protein family interact with the cytoskeletal protein alpha-fodrin. J Biol Chem 276:40104-40112.

Boeckers TM, Bockmann J, Kreutz MR, Gundelfinger ED (2002) ProSAP/ Shank proteins-a family of higher order organizing molecules of the postsynaptic density with an emerging role in human neurological disease. J Neurochem 81:903-910.

Bonaglia MC, Giorda R, Borgatti R, Felisari G, Gagliardi C, Selicorni A, Zuffardi O (2001) Disruption of the ProSAP2 gene in a $\mathrm{t}(12 ; 22)(\mathrm{q} 24.1$; q13.3) is associated with the 22q13.3 deletion syndrome. Am J Hum Genet 69:261-268.

Bonaglia MC, Giorda R, Beri S, De Agostini C, Novara F, Fichera M, Grillo L, Galesi O, Vetro A, Ciccone R, Bonati MT, Giglio S, Guerrini R, Osimani S, Marelli S, Zucca C, Grasso R, Borgatti R, Mani E, Motta C, et al. (2011) Molecular mechanisms generating and stabilizing terminal 22q13 deletions in 44 subjects with Phelan/McDermid syndrome. PLoS Genet 7:e1002173.

Bourgeron T (2009) A synaptic trek to autism. Curr Opin Neurobiol 19:231-234.

Bozdagi O, Sakurai T, Papapetrou D, Wang X, Dickstein DL, Takahashi N, Kajiwara Y, Yang M, Katz AM, Scattoni ML, Harris MJ, Saxena R, Silverman JL, Crawley JN, Zhou Q, Hof PR, Buxbaum JD (2010) Haploinsufficiency of the autism-associated Shank3 gene leads to deficits in synaptic function, social interaction, and social communication. Mol Autism 1:15.

Buxbaum JD (2009) Multiple rare variants in the etiology of autism spectrum disorders. Dialogues Clin Neurosci 11:35-43.

Chadman KK, Gong S, Scattoni ML, Boltuck SE, Gandhy SU, Heintz N, Crawley JN (2008) Minimal aberrant behavioral phenotypes of neuroligin-3 R451C knockin mice. Autism Res 1:147-158.

Crawley J, Goodwin FK (1980) Preliminary report of a simple animal behavior model for the anxiolytic effects of benzodiazepines. Pharmacol Biochem Behav 13:167-170.

Crawley JN, Chen T, Puri A, Washburn R, Sullivan TL, Hill JM, Young NB, Nadler JJ, Moy SS, Young LJ, Caldwell HK, Young WS (2007) Social approach behaviors in oxytocin knockout mice: comparison of two independent lines tested in different laboratory environments. Neuropeptides 41:145-163.

Delahaye A, Toutain A, Aboura A, Dupont C, Tabet AC, Benzacken B, Elion J, Verloes A, Pipiras E, Drunat S (2009) Chromosome 22q13.3 deletion syndrome with a de novo interstitial 22q13.3 cryptic deletion disrupting SHANK3. Eur J Med Genet 52:328-332.

Dhar SU, del Gaudio D, German JR, Peters SU, Ou Z, Bader PI, Berg JS, Blazo M, Brown CW, Graham BH, Grebe TA, Lalani S, Irons M, Sparagana S, Williams M, Phillips JA 3rd, Beaudet AL, Stankiewicz P, Patel A, Cheung SW, et al. (2010) 22q13.3 deletion syndrome: clinical and molecular analysis using array CGH. Am J Med Genet A 152A:573-581.

Durand CM, Betancur C, Boeckers TM, Bockmann J, Chaste P, Fauchereau F, Nygren G, Rastam M, Gillberg IC, Anckarsäter H, Sponheim E, GoubranBotros H, Delorme R, Chabane N, Mouren-Simeoni MC, de Mas P, Bieth E, Rogé B, Héron D, Burglen L, et al. (2007) Mutations in the gene encoding the synaptic scaffolding protein SHANK3 are associated with autism spectrum disorders. Nat Genet 39:25-27.

Durand CM, Perroy J, Loll F, Perrais D, Fagni L, Bourgeron T, Montcouquiol M, Sans N (2012) SHANK3 mutations identified in autism lead to modification of dendritic spine morphology via an actin-dependent mechanism. Mol Psychiatry 17:71-84.

Edelson SM, Edelson MG, Kerr DC, Grandin T (1999) Behavioral and physiological effects of deep pressure on children with autism: a pilot study evaluating the efficacy of Grandin's Hug Machine. Am J Occup Ther 53:145-152.

Gauthier J, Spiegelman D, Piton A, Lafrenière RG, Laurent S, St-Onge J, Lapointe L, Hamdan FF, Cossette P, Mottron L, Fombonne E, Joober R, Marineau C, Drapeau P, Rouleau GA (2009) Novel de novo SHANK3 mutation in autistic patients. Am J Med Genet B Neuropsychiatr Genet 150B:421-424.

Ghaziuddin M, Butler E (1998) Clumsiness in autism and Asperger syndrome: a further report. J Intellect Disabil Res 42:43-48.

Hammond RS, Tull LE, Stackman RW (2004) On the delay-dependent involvement of the hippocampus in object recognition memory. Neurobiol Learn Mem 82:26-34.
Herbert MR (2011) SHANK3, the synapse, and autism. N Engl J Med 365:173-175.

Holmes A, Hollon TR, Gleason TC, Liu Z, Dreiling J, Sibley DR, Crawley JN (2001) Behavioral characterization of dopamine D5 receptor null mutant mice. Behav Neurosci 115:1129-1144.

Holmes A, Li Q, Koenig EA, Gold E, Stephenson D, Yang RJ, Dreiling J, Sullivan T, Crawley JN (2005) Phenotypic assessment of galanin overexpressing and galanin receptor R1 knockout mice in the tail suspension test for depression-related behavior. Psychopharmacology (Berl) 178:276-285.

Houlihan LM, Harris SE, Luciano M, Gow AJ, Starr JM, Visscher PM, Deary IJ (2009) Replication study of candidate genes for cognitive abilities: the Lothian Birth Cohort 1936. Genes Brain Behav 8:238-247.

Humphrey N, Symes W (2011) Peer interaction patterns among adolescents with autistic spectrum disorders (ASDs) in mainstream school settings. Autism 15:397-419.

Kim SH, Lord C (2010) Restricted and repetitive behaviors in toddlers and preschoolers with autism spectrum disorders based on the Autism Diagnostic Observation Schedule (ADOS). Autism Res 3:162-173.

Lloyd M, Macdonald M, Lord C (2011) Motor skills of toddlers with autism spectrum disorders. Autism. Advance online publication. Retrieved March 14, 2012. doi:10.1177/1362361311402230.

Lord C, Cook EH, Leventhal BL, Amaral DG (2000) Autism spectrum disorders. Neuron 28:355-363.

Lord C, Leventhal BL, Cook EH Jr (2001) Quantifying the phenotype in autism spectrum disorders. Am J Med Genet 105:36-38.

McFarlane HG, Kusek GK, Yang M, Phoenix JL, Bolivar VJ, Crawley JN (2008) Autism-like behavioral phenotypes in BTBR T $+\mathrm{tf} / \mathrm{J}$ mice. Genes Brain Behav 7:152-163.

Misceo D, Rødningen OK, Barøy T, Sorte H, Mellembakken JR, Strømme P, Fannemel M, Frengen E (2011) A translocation between Xq21.33 and $22 \mathrm{q} 13.33$ causes an intragenic SHANK3 deletion in a woman with PhelanMcDermid syndrome and hypergonadotropic hypogonadism. Am J Med Genet A 155A:403-408.

Miyakawa T, Yared E, Pak JH, Huang FL, Huang KP, Crawley JN (2001) Neurogranin null mutant mice display performance deficits on spatial learning tasks with anxiety related components. Hippocampus 11:763-775

Moessner R, Marshall CR, Sutcliffe JS, Skaug J, Pinto D, Vincent J, Zwaigenbaum L, Fernandez B, Roberts W, Szatmari P, Scherer SW (2007) Contribution of SHANK3 mutations to autism spectrum disorder. Am J Hum Genet 81:1289-1297.

Moruzzi S, Ogliari A, Ronald A, Happé F, Battaglia M (2011) The nature of covariation between autistic traits and clumsiness: a twin study in a general population sample. J Autism Dev Disord 41:1665-1674.

Moy SS, Nadler JJ, Young NB, Perez A, Holloway LP, Barbaro RP, Barbaro JR, Wilson LM, Threadgill DW, Lauder JM, Magnuson TR, Crawley JN (2007) Mouse behavioral tasks relevant to autism: phenotypes of 10 inbred strains. Behav Brain Res 176:4-20.

Moy SS, Nadler JJ, Young NB, Nonneman RJ, Segall SK, Andrade GM, Crawley JN, Magnuson TR (2008) Social approach and repetitive behavior in eleven inbred mouse strains. Behav Brain Res 191:118-129.

Paylor R, Zhao Y, Libbey M, Westphal H, Crawley JN (2001) Learning impairments and motor dysfunctions in adult Lhx5-deficient mice displaying hippocampal disorganization. Physiol Behav 73:781-792.

Peça J, Feliciano C, Ting JT, Wang W, Wells MF, Venkatraman TN, Lascola CD, Fu Z, Feng G (2011) Shank3 mutant mice display autistic-like behaviours and striatal dysfunction. Nature 472:437-442.

Pellock JM (2004) Understanding co-morbidities affecting children with epilepsy. Neurology 62:S17-S23.

Phelan MC (2008) Deletion 22q13.3 syndrome. Orphanet J Rare Dis 3:14.

Qin J, Jia M, Wang L, Lu T, Ruan Y, Liu J, Guo Y, Zhang J, Yang X, Yue W, Zhang D (2009) Association study of SHANK3 gene polymorphisms with autism in Chinese Han population. BMC Med Genet 10:61.

Rampon C, Tsien JZ (2000) Genetic analysis of learning behavior-induced structural plasticity. Hippocampus 10:605-609.

Rinehart NJ, Bradshaw JL, Brereton AV, Tonge BJ (2001) Movement preparation in high-functioning autism and Asperger disorder: a serial choice reaction time task involving motor reprogramming. J Autism Dev Disord 31:79-88.

Roullet FI, Wöhr M, Crawley JN (2011) Female urine-induced male mice 
ultrasonic vocalizations, but not scent-marking, is modulated by social experience. Behav Brain Res 216:19-28.

Roussignol G, Ango F, Romorini S, Tu JC, Sala C, Worley PF, Bockaert J, Fagni L (2005) Shank expression is sufficient to induce functional dendritic spine synapses in aspiny neurons. J Neurosci 25:3560-3570.

Scattoni ML, McFarlane HG, Zhodzishsky V, Caldwell HK, Young WS, Ricceri L, Crawley JN (2008a) Reduced ultrasonic vocalizations in vasopressin 1b knockout mice. Behav Brain Res 187:371-378.

Scattoni ML, Gandhy SU, Ricceri L, Crawley JN (2008b) Unusual repertoire of vocalizations in the BTBR T+tf/J mouse model of autism. PLoS One 3:e3067.

Scattoni ML, Ricceri L, Crawley JN (2011) Unusual repertoire of vocalizations in adult BTBR $\mathrm{T}+\mathrm{tf} / \mathrm{J}$ mice during three types of social encounters. Genes Brain Behav 10:44-56.

Sheng M, Kim E (2000) The Shank family of scaffold proteins. J Cell Sci 113:1851-1856.

Silverman JL, Tolu SS, Barkan CL, Crawley JN (2010a) Repetitive selfgrooming behavior in the BTBR mouse model of autism is blocked by the mGluR5 antagonist MPEP. Neuropsychopharmacology 35:976-989.

Silverman JL, Yang M, Lord C, Crawley JN (2010b) Behavioural phenotyping assays for mouse models of autism. Nat Rev Neurosci 11:490-502.

Silverman JL, Yang M, Turner SM, Katz AM, Bell DB, Koenig JI, Crawley JN (2010c) Low stress reactivity and neuroendocrine factors in the BTBR $\mathrm{T}+\mathrm{tf} / \mathrm{J}$ mouse model of autism. Neuroscience 171:1197-1208.

Silverman JL, Turner SM, Barkan CL, Tolu SS, Saxena R, Hung AY, Sheng M, Crawley JN (2011) Sociability and motor functions in Shank1 mutant mice. Brain Res 1380:120-137.

Stack CM, Lim MA, Cuasay K, Stone MM, Seibert KM, Spivak-Pohis I, Crawley JN, Waschek JA, Hill JM (2008) Deficits in social behavior and reversal learning are more prevalent in male offspring of VIP deficient female mice. Exp Neurol 211:67-84.

Steiner RA, Hohmann JG, Holmes A, Wrenn CC, Cadd G, Juréus A, Clifton DK, Luo M, Gutshall M, Ma SY, Mufson EJ, Crawley JN (2001) Galanin transgenic mice display cognitive and neurochemical deficits characteristic of Alzheimer's disease. Proc Natl Acad Sci U S A 98:4184-4189.

Strenge S, Froster UG, Kujat A, Bernhard M, Merkenschlager A (2008) Muscular hypotonia, developmental retardation, speech delay and mildly dysmorphic features: 22q13 deletion syndrome (Phelan-McDermid Syndrome) as an important differential diagnosis (in German). Klin Padiatr 220:318-320.

Sykes NH, Toma C, Wilson N, Volpi EV, Sousa I, Pagnamenta AT, Tancredi R, Battaglia A, Maestrini E, Bailey AJ, Monaco AP; International Molecular Genetic Study of Autism Consortium (IMGSAC) (2009) Copy number variation and association analysis of SHANK3 as a candidate gene for autism in the IMGSAC collection. Eur J Hum Genet 17:1347-1353.
Tsai LY (1999) Psychopharmacology in autism. Psychosom Med 61: 651-665.

Tu JC, Xiao B, Naisbitt S, Yuan JP, Petralia RS, Brakeman P, Doan A, Aakalu VK, Lanahan AA, Sheng M, Worley PF (1999) Coupling of mGluR/ Homer and PSD-95 complexes by the Shank family of postsynaptic density proteins. Neuron 23:583-592.

Verpelli C, Dvoretskova E, Vicidomini C, Rossi F, Chiappalone M, Schoen M, Di Stefano B, Mantegazza R, Broccoli V, Böckers TM, Dityatev A, Sala C (2011) Importance of Shank3 protein in regulating metabotropic glutamate receptor 5 (mGluR5) expression and signaling at synapses. J Biol Chem 286:34839-34850.

Wang X, McCoy PA, Rodriguiz RM, Pan Y, Je HS, Roberts AC, Kim CJ, Berrios J, Colvin JS, Bousquet-Moore D, Lorenzo I, Wu G, Weinberg RJ, Ehlers MD, Philpot BD, Beaudet AL, Wetsel WC, Jiang YH (2011) Synaptic dysfunction and abnormal behaviors in mice lacking major isoforms of Shank3. Hum Mol Genet 20:3093-3108.

West L, Waldrop J, Brunssen S (2009) Pharmacologic treatment for the core deficits and associated symptoms of autism in children. J Pediatr Health Care 23:75-89.

Wöhr M, Roullet FI, Crawley JN (2011) Reduced scent marking and ultrasonic vocalizations in the BTBR $\mathrm{T}+\mathrm{tf} / \mathrm{J}$ mouse model of autism. Genes Brain Behav 10:35-43.

Wrenn CC, Kinney JW, Marriott LK, Holmes A, Harris AP, Saavedra MC, Starosta G, Innerfield CE, Jacoby AS, Shine J, Iismaa TP, Wenk GL, Crawley JN (2004) Learning and memory performance in mice lacking the GAL-R1 subtype of galanin receptor. Eur J Neurosci 19:1384-1396.

Yang M, Crawley JN (2009) Simple behavioral assessment of mouse olfaction. Curr Protoc Neurosci Chapter 8:Unit 8.24.

Yang M, Zhodzishsky V, Crawley JN (2007) Social deficits in BTBR T+tf/J mice are unchanged by cross-fostering with C57BL/6J mothers. Int J Dev Neurosci 25:515-521.

Yang M, Clarke AM, Crawley JN (2009) Postnatal lesion evidence against a primary role for the corpus callosum in mouse sociability. Eur J Neurosci 29:1663-1677.

Yang M, Perry K, Weber MD, Katz AM, Crawley JN (2011a) Social peers rescue autism-relevant sociability deficits in adolescent mice. Autism Res $4: 17-27$.

Yang M, Scattoni ML, Chadman CC, Silverman JL, Crawley JN (2011b) Behavioral evaluation of genetic mouse models of autism. In: Autism spectrum disorders (Amaral DG, Dawson G, Geschwind DH, eds), pp 906-934. Oxford: Oxford UP.

Yang M, Silverman JL, Crawley J (2011c) Automated three-chambered social approach task for mice. Curr Protoc Neurosci Chapter 8:Unit 8.26. 